1 Preprint version, Reference: Blyth, Anna, Beatrice Di Napoli, Francesco Parisse, Zahir Namourah, Elsa

2 Anglade, Anna-Maria Giatreli, Hugo Rodrigues, and Tiago Miguel Ferreira. 2020. "Assessment and

3 Mitigation of Seismic Risk at the Urban Scale: An Application to the Historic City Center of Leiria,

4 Portugal." Bulletin of Earthquake Engineering 18 (6): 2607-34. https://doi.org/10.1007/s10518-020-

$5 \quad 00795-2$.

\title{
Assessment and Mitigation of Seismic Risk at the Urban Scale: An Application to the Historic City Center of Leiria, Portugal
}

Anna Blyth ${ }^{1}$, Beatrice Di Napoli ${ }^{1}$, Francesco Parisse ${ }^{1}$, Zahir Namourah ${ }^{1}$, Elsa Anglade ${ }^{1,2}$, Anna-Maria Giatreli ${ }^{1}$,

${ }^{1}$ ISISE, Institute for Science and Innovation for Bio-Sustainability (IB-S), Department of Civil Engineering, University of
Minho, Portugal Hugo Rodrigues ${ }^{3}$, Tiago Miguel Ferreira ${ }^{1, *}$

${ }^{2}$ Département Génie Civil, Ecole Normal Supérieure de Paris-Saclay, France

${ }^{3}$ RISCO, Department of Civil Engineering, Polytechnic Institute of Leiria, Portugal

*Corresponding author: tmferreira@civil.uminho.pt

\begin{abstract}
The implementation of a culture of seismic risk preparedness is becoming increasingly critical in Europe as the building stock ages and the awareness about seismic risk rises. In this context, the assessment of the seismic vulnerability of existing buildings, followed by the implementation of appropriate retrofitting solutions, can help to substantially reduce the levels of physical damage and economic impact of future events. The central region of Portugal is particularly susceptible to large seismic events and is characterized by the prevalence of historic masonry buildings. This work aims to validate assessment methods for the risk of historical city centers in order to propose management strategies for municipalities and assess the economic impact of large-scale seismic retrofitting. To do this, an application of these methods was performed on the historical city center of Leiria. An in-depth inspection was performed of the entire center and the results were compiled into a database. Using an index-based seismic vulnerability assessment approach, a vulnerability assessment was made for each building. Based on vulnerability and predicted damage, estimates of human and economic losses were made for the city center before and after retrofitting to justify interventions on a broad scale.
\end{abstract}

Keywords: Risk Management, Seismic Vulnerability Assessment, Historic Centers, Masonry Buildings, Retrofitting Strategies.

\section{Introduction}

The cultural value of historical city centers can be considered the result of long-term processes dealing with ethnological, political, economic, architectural and artistic values (Vicente et al. 2015). Their unique identity should be recognized and characterized by analyzing the urban morphology and by understanding the history and cultural background. Any potential intervention should be based on this knowledge and be a result of a systematic method of assessment and recording that ensures compatibility during the urban regeneration process. A strategic and standardized methodology with a large scale, sustainable, and multidisciplinary approach for defining outlines and procedures of intervention is required even though this framework is likely to have some singularities since each case is unique (Ferreira et al. 2015). The vulnerabilities of historical city centers are still not completely understood by governments. The implementation of risk policy is limited even though the scientific community has 
increased its research on this issue providing guidelines, methodologies, technologies, and tools to evaluate and monitor the existing framework and predict potential scenarios (Ferreira et al. 2017a). Although some methodologies are more accurate in terms of results, they may be not economically viable, so simplified seismic vulnerability assessment methods can play an important role in developing vulnerability scenarios at urban or building scales (Ferreira et al. 2017a). This article is aimed at evaluating the vulnerability of the historical city center of Leiria, Portugal, by using the vulnerability index methodology developed by Vicente et al. (2011) based on the Italian GNDT II level approach (GNDT 1994), with the quantification of the uncertainty through the introduction of the concept of parameter confidence factor. In an attempt to account for the uncertainty associated with the evaluation, this confidence factor opens the door to future advances on the quantification of that uncertainty on the risk assessment results. The present work aims to provide quantitative data about the risks associated with seismicity of Leiria, guiding the municipality through the making of informed decisions about a risk management plan and retrofitting strategies.

\section{The Historical City Center of Leiria}

\subsection{Overview of the case study}

Leiria, located in central Portugal, is one of the main cities between Coimbra and Lisbon. It is widely known that the Portugal mainland is a slow seismic deforming region, where the interaction between the African and Eurasian plates can be responsible for large earthquakes. In the last century, the region has experienced at least 116 earthquakes with intensities equal or larger than III on the EMS-98 macroseismic intensity scale (Teves-Costa et al. 2019). The most notable for the seismic history of Portugal is the 1755 Lisbon earthquake $(8.5 \pm 0.3 \mathrm{Mw})$ that caused great damage in the Algarve and Lisbon regions as well as in Leiria (Carvalho and Aveleira n.d.). According to maximum intensity maps (MIM) available for Portugal mainland, intensity VII or VIII can be identified as representative of the seismicity of the city (Teves-Costa et al. 2019). Thus, Leiria is at acute risk of destructive earthquakes and should prepare adequate risk management strategies.

The foundation of the city can be traced back to 1135 when D. Afonso Henriques built its castle (Mattoso 1985). Since then, it has flourished thanks to its position first as an outpost to the Moorish domains and later as a commercial hub. The urban configuration developed in relation to the castle and the two landmarks of the mains square and the cathedral. Its layout is defined by the fundamental axis of Rua Direita and related streets branching perpendicularly. The present work focused on a limited portion $\left(45,000 \mathrm{~m}^{2}\right)$ of the city corresponding to the historical center that, in preparation for fieldwork, was divided into three zones (Figure 1), and each building was identified with a unique identification code.

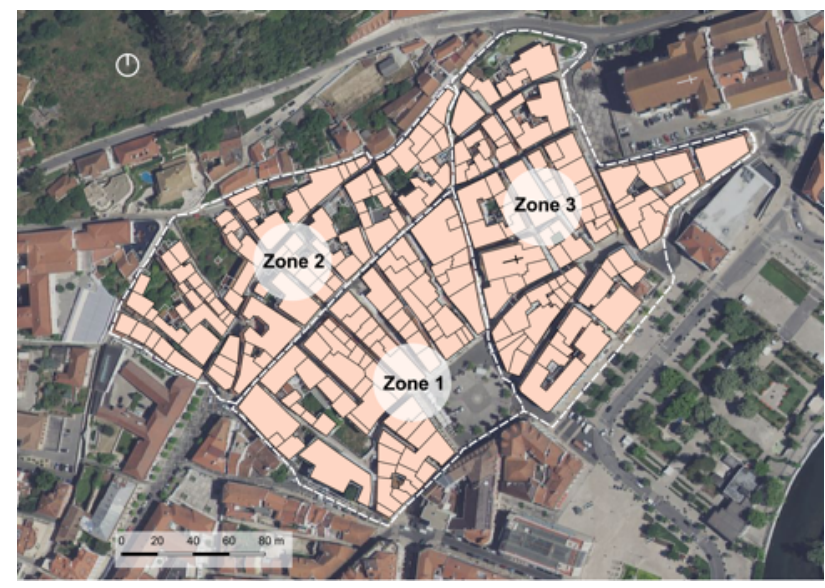

Figure 1. Case study zones, adapted from Anglade et al. (2020)

Among the analyzed buildings, 49.7\% were multi familiar, 38.2\% single familiar, 32.5\% with mixed use, and $39.5 \%$ of the buildings were unoccupied. According to a socio-demographic census carried by 
the municipality of Leiria there are 315 residents in the city center divided into the three zones (Dinis 2006), see Table 1.

Table 1. Demographic data presented by zone and by age groups (Dinis 2006)

\begin{tabular}{ccccccc}
\hline \multicolumn{7}{c}{ Residents by Age } \\
\hline Zone & Age 0-4 & Age 5-13 & Age 13-24 & Age 25-65 & Age $>$ 65 & Total \\
\hline Zone 1 & 6 & 8 & 9 & 67 & 30 & 120 \\
\hline Zone 2 & 3 & 7 & 13 & 50 & 22 & 95 \\
\hline Zone 3 & 0 & 3 & 5 & 58 & 34 & 100 \\
\hline Total & 9 & 18 & 27 & 175 & 86 & 315 \\
\hline
\end{tabular}

\subsection{Building characterization}

The area is composed of 232 buildings divided into three main typologies: concrete (RC) buildings, $31.1 \%$ of the analyzed building stock; mixed structures, $7.9 \%$; and masonry buildings, $61 \%$, which represent the main focus of this work. RC buildings fall outside the scope of the study and are omitted from the data.

\subsubsection{Geometrical features}

The study area is composed of a fairly homogeneous building stock with common features that were easily identifiable during fieldwork. The buildings are generally part of an aggregate, and they tend to be of 3-4 stories and regular in both plan configuration and height. The façade layout characterization is also notable, as it has a great influence on the shear resistance and in-plane response of the façade walls. The façade openings were found to be of notable size and fairly regular in layout for façades facing the main streets and squares, see Figure 2 (a) and (b), while in secondary streets they present a less regular configuration and are smaller in size, Figure 2 (c). In some cases, sources of irregularity both in plan and elevation were introduced by later interventions carried out on the buildings, such as additions, super elevations, creation of larger openings at the ground floors, floor slab replacements, etc.

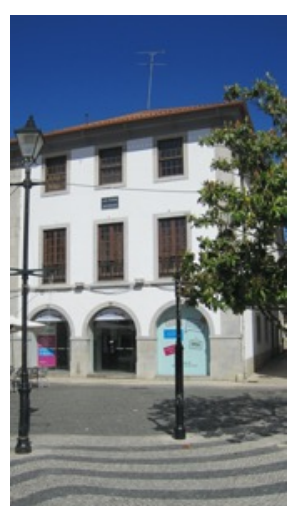

(a)

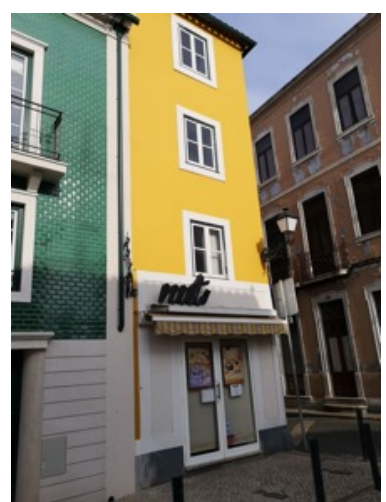

(b)

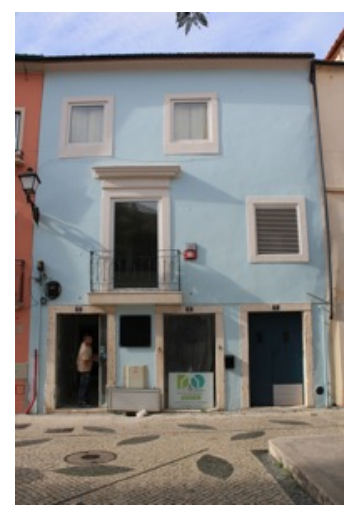

(c)

Figure 2. Regular big openings facing of a building facing the cathedral's square (a), a minor square (b) and irregular size and layout openings of a secondary street (c)

\subsubsection{Materials and connections}

External inspections were used to evaluate the quality of masonry because deterioration of the external renders allowed for direct observation of the material underneath. The external walls of the buildings are mainly composed of stone masonry, usually limestone units of different sizes sometimes mixed with units of other materials, e.g. clay bricks, marlstones, etc. The units' arrangement has sub-horizontal mortar joints, but the alignment of the vertical joints does not indicate a good quality masonry (Borri et al. 2015). In addition, there is large variability in the size and shape of the units, Figure 3 . The walls' thicknesses range from $0.4 \mathrm{~m}$ to $1.0 \mathrm{~m}$ with an average of $0.7 \mathrm{~m}$ and are a three-leaf arrangement with weak inner filling and lack of connections. The mechanical properties of the masonry were identified 

gennaio 2019 n. 7 C.S.LL.PP. 2019) and confirmed by flat jack tests performed by Pinheiro et al. (2017).

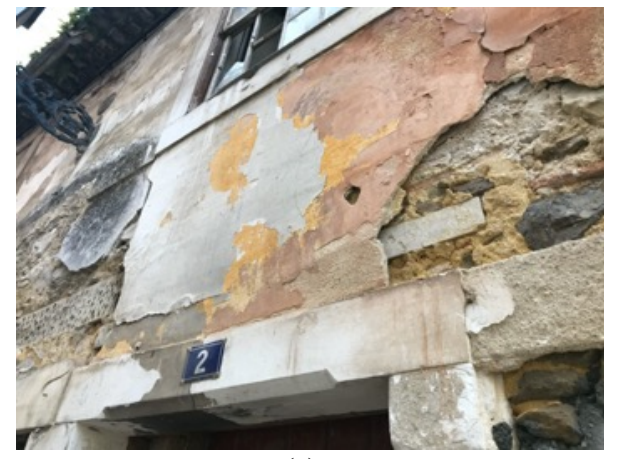

(a)

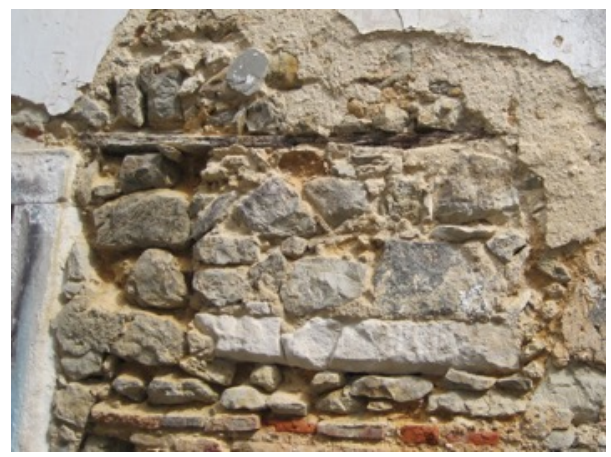

(b)

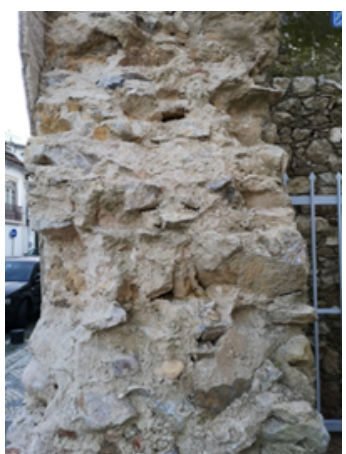

(c)

Figure 3. Rubble stone masonry with other material units: sub-horizontal arrangement $(a, b)$ and cross section (c) of some masonry walls in Leiria

Good wall-to-wall connection was often evidenced by the presence of large stones in the façade corners, Figure 4 (a). Thus, when this feature was detected, good quality of the wall-to-wall connection was assumed for the building. If this was not observed, a bad quality connection and improper interlocking was assumed. This assumption was supported by observations of large vertical and diagonal cracks, an indication of a poor connection between the internal and external walls that allows for independent behavior and rotation of the façade walls, Figure 4 (b) and (c).

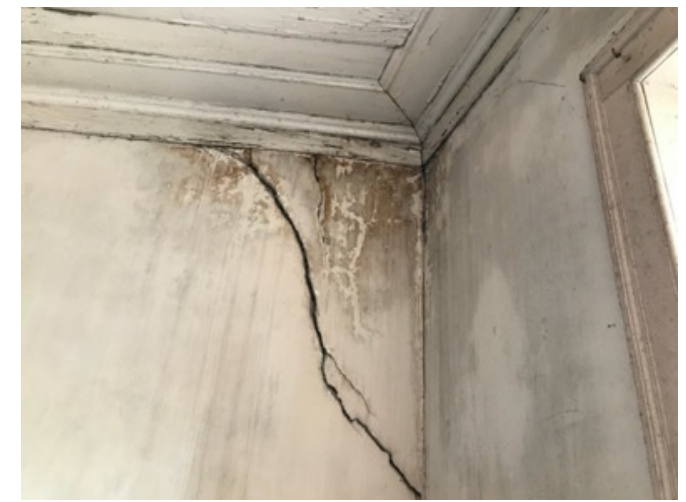

(a)

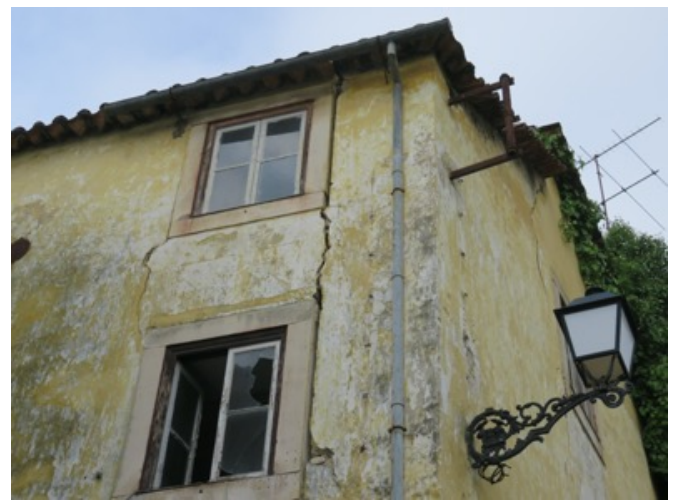

(b)

Figure 4. Bad quality connections between orthogonal walls evidenced by diagonal cracks on internal walls (a) and by detachment cracks on the corners (b)

Three floor types were observed in the study area: concrete slabs, metallic structures, and timber floors. The first two typologies were observed in just a few cases in buildings that were recently restored, while the third type was found in the majority of buildings. The timber floors are composed of pine beams directly supported by the bearing wall or by a primary order of timber beams, Figure 5 (a). No tie rods or metallic elements were observed to improve connections between the floor and walls. Thus, a conservative assumption was made when information about the floor was not available: the presence of a flexible timber floor with weak connections to the walls and no presence of tie rods was assumed.

Few roofing systems were accessible during the fieldwork. However, all of the roofs inspected consisted of timber truss elements. In some cases, half trusses were observed, but in most cases king post trusses or simple trusses were used, Figure 5 (b). Additionally, in all the inspected roofs, the truss structure was connected to the walls through a dormant beam extending all along the perimeter with load distribution and tying function, Figure 5 (c). This beam is a mixed masonry-timber element that indicates that the 
roof weight and thrust are properly distributed to the perimeter walls and a good connection between walls and roof is assured. It was assumed that inaccessible roofs are similar to the ones inspected. These assumptions, namely the non-impulsive nature of the roof and the presence of a perimeter ribbon, might lead to an underestimation of the vulnerability of the buildings to the roofing system interaction. However, the assumptions made are supported by observations made in the field inspections and by the knowledge of the traditional construction techniques of the area. For these reasons the assumptions made are considered sufficiently cautious.

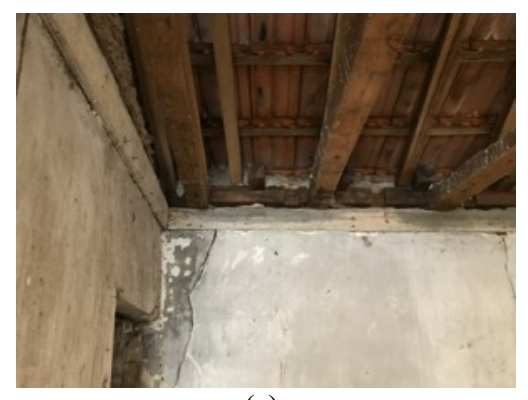

(a)

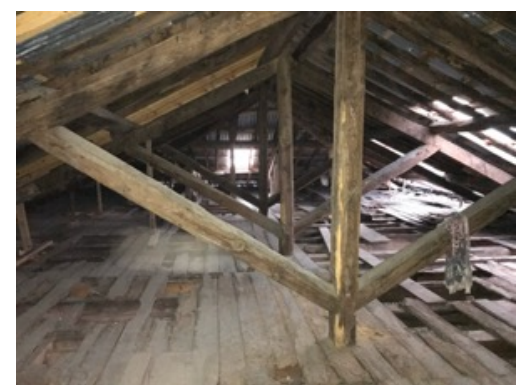

(b)

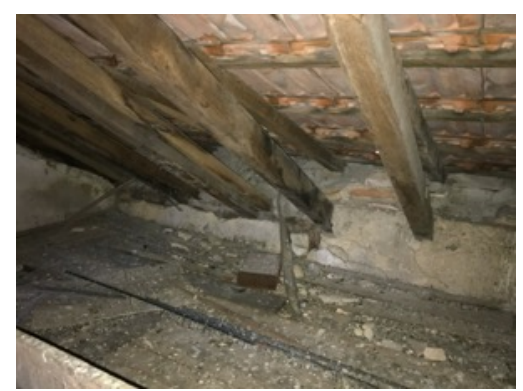

(c)

Figure 5. Example of a two-order timber floor with connection to the perimeter wall (a), timber king post truss of a roof (b), mixed masonry-timber perimeter ribbon of the roof (c)

\section{6}

\section{Inspection procedure and database}

All the buildings in the study area were assessed on site to collect the required data for the computation of the vulnerability indices by using a detailed checklist built for this purpose. It was developed to evaluate each construction element of the relevant (non-reinforced concrete) buildings based on scientific knowledge and experience with the chosen methods and site of the engineers conducting the evaluations. The checklist was adapted from a Portuguese interpretation of the Italian Gruppo nazionale per la difesa dai terremoti (GNDT) checklist for seismic vulnerability evaluations of the building stock in Italy, thus combining expertise on seismic evaluation and regional construction methods (GNDT 2003; dos Santos Gomes 2016). In addition, the necessary data were identified from studies performed by Vicente et al. (2011) and Ferreira (2010) as those most important to collect for the computation of the vulnerability index values. Any necessary information that could not be obtained from a groundlevel visual inspection alone was left blank on the checklist to be completed with another data source (i.e. Google Maps, Google Earth, or the municipality site map) or expert assumption. The data contained in the checklists was manually inputted into a spreadsheet database to create a digital record and to automate some later steps of the work. In fact, the vulnerability index tool spreadsheet automatically pulled information from the database without needing to re-enter information manually. It was only necessary to manually enter a small amount of the information required that was not possible to gather directly or that was not related to singular buildings.

Once all the indices and seismic vulnerability indicators for each building were computed, e.g. mean damage grade, probability of collapse, probability of unusability, etc., the results were plotted spatially with a general planning tool. In many cases, without the use of a representative approach that allows the technicians and the decision makers to acquire a global view of the area and of the results of the assessment, the risk management effectiveness can be compromised (Ferreira et al. 2013). For this reason, a multi-purpose tool connected to a relational database within a GIS environment was used in this work. The GIS application software (QGIS 3.4.4 - Madeira) represents each building by its plan footprint to plot the results of the assessment. All the buildings in the study area were inspected from the exterior; of these, $6.2 \%$ were inspected from the interior as well, see Figure 6. Exterior inspections were performed from ground level and at each accessible façade on the building. Approximately $70 \%$ of the data on the checklist could be obtained from an exterior inspection alone. When an inside 
inspection was possible, more precise information regarding the floor slabs and the roofing system was gathered along with more information regarding the state of conservation. In most cases the type of inspection carried out did not impose a significant change in the vulnerability index. However, the information gathered during the internal inspections was used as a representative sample of the remaining building stock.

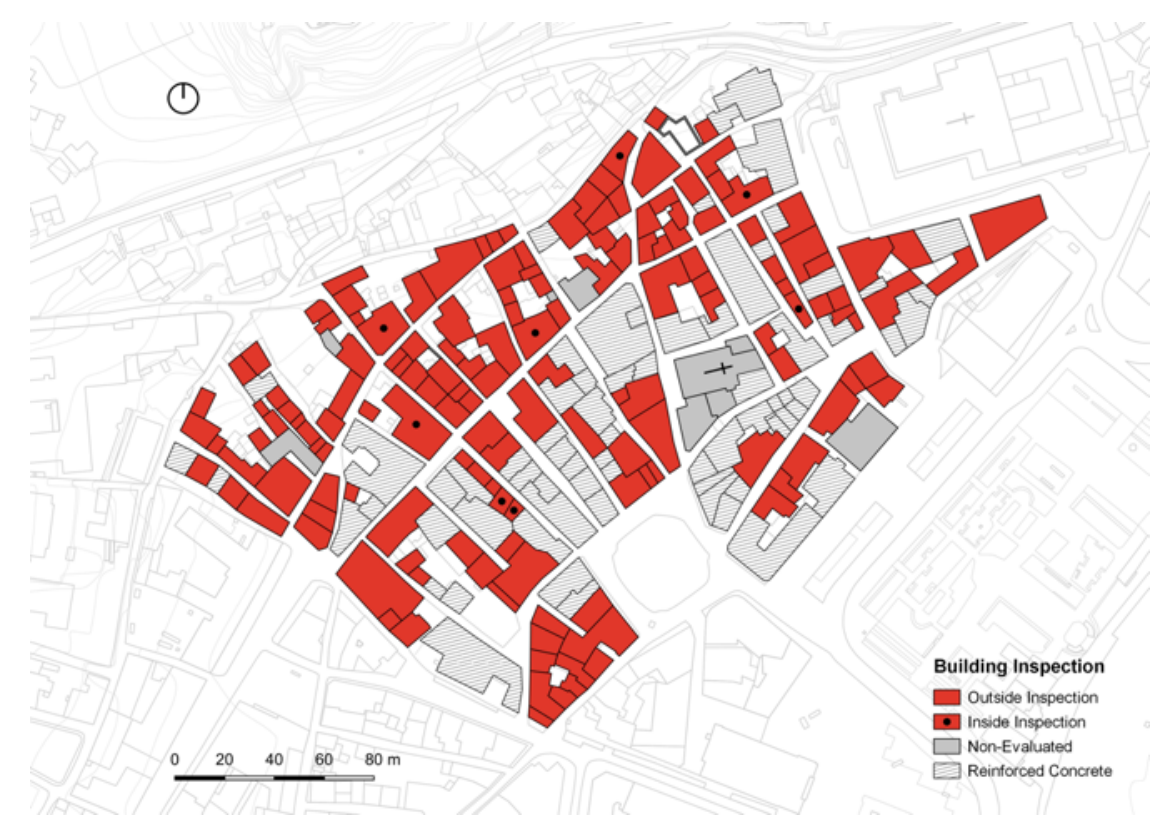

Figure 6. Map with the type of inspection, adapted from Anglade et al. (2020)

\section{Vulnerability index methodology}

The vulnerability assessment was carried out using a hybrid approach based on the GNDT II level approach for the masonry buildings (GNDT 2003). The method was proposed by Vicente et al. (2011) and developed by other authors (Ferreira 2010). It aims to estimate possible losses and post-seismic scenarios through a simplified assessment that utilizes post-seismic damage observations and survey data on the elements that define building damage (Maio et al. 2016). The method has been successfully adapted to the Portuguese historical building environment (Ferreira et al. 2017a; Maio et al. 2016; Vicente et al. 2011) and is calibrated according to damage data collected for the magnitude VII earthquake that struck the Azores archipelago in 1998 (Ferreira et al. 2017a). It is worth noting in this regard that, although the method is not specifically calibrated for this case study (which would be impossible since no damage data is available), the fact that it has been calibrated based a similar building typology, with similar constructive and geometrical features, allows to assume the validity of the results. As explained in the following, possible differences in the mechanical characteristics of the structural elements are considered and controlled by the method.

The method evaluates 14 parameters that affect the seismic performance of the building stock. A vulnerability class $\left(c_{v i}\right)$ is assigned to these parameters with increasing vulnerability: A, B, C, and D and a weight $\left(p_{i}\right)$ is given ranging from 0.5 for the least important parameters to 2.5 for those considered most important (Table 2). The parameters are used evaluate a single building in an aggregate and are organized into four groups: structural building system, irregularities and interaction, floor slabs and roof, conservation status and other elements. A total vulnerability index $I_{v}$ is calculated with Equation (1) by computing the weighted sum of the parameters multiplied by their specific weight assigned as a meaning of importance in the definition of seismic response. The total vulnerability index takes on an integer value in the range between 0 and 750; it is then normalized to a global vulnerability index $\left(I_{v}\right)$ ranging between 0 and 100 . 


$$
I_{v}=\sum_{i=1}^{14} c_{v i} \times p_{i}
$$

194 Each parameter was evaluated based on expert opinion but has inherent uncertainty. To account for this, 195 confidence levels were evaluated and are presented in Section 5.2.

196 Table 2. Vulnerability index associated parameters, classes and post-calibration weights pi (Ferreira et al. 2017a)

\begin{tabular}{|c|c|c|c|c|c|c|}
\hline \multirow{2}{*}{ Parameters } & \multicolumn{4}{|c|}{ Class, $C_{v i}$} & \multirow{2}{*}{$\begin{array}{c}\text { Weight } \\
p_{i}\end{array}$} & \multirow{2}{*}{$\begin{array}{c}\text { Relative } \\
\text { weight }\end{array}$} \\
\hline & $\mathbf{A}$ & $\mathbf{B}$ & $\mathbf{C}$ & $\mathbf{D}$ & & \\
\hline \multicolumn{7}{|l|}{ Group 1. Structural building system } \\
\hline P1. Type of the resisting system & 0 & 5 & 20 & 50 & 2.50 & \multirow{6}{*}{$50 / 100$} \\
\hline P2. Quality of the resisting system & 0 & 5 & 20 & 50 & 2.50 & \\
\hline P3. Conventional strength & 0 & 5 & 20 & 50 & 1.00 & \\
\hline P4. Maximum distance between the walls & 0 & 5 & 20 & 50 & 0.50 & \\
\hline P5. Number of floors & 0 & 5 & 20 & 50 & 0.50 & \\
\hline P6. Location and soil condition & 0 & 5 & 20 & 50 & 0.50 & \\
\hline \multicolumn{7}{|l|}{ Group 2. Irregularities and interaction } \\
\hline P7. Aggregate position and interaction & 0 & 5 & 20 & 50 & 1.50 & \multirow{4}{*}{$20 / 100$} \\
\hline P8. Plan configuration & 0 & 5 & 20 & 50 & 0.50 & \\
\hline P9. Height regularity & 0 & 5 & 20 & 50 & 0.50 & \\
\hline P10. Wall facade openings and alignments & 0 & 5 & 20 & 50 & 0.50 & \\
\hline \multicolumn{7}{|l|}{ Group 3. Floor slabs and roofs } \\
\hline P11. Horizontal diaphragms & 0 & 5 & 20 & 50 & 0.75 & \multirow{2}{*}{$18 / 100$} \\
\hline P12. Roofing system & 0 & 5 & 20 & 50 & 2.00 & \\
\hline \multicolumn{7}{|c|}{ Group 4. Conservation status and other elements } \\
\hline P13. Fragilities and conservation status & 0 & 5 & 20 & 50 & 1.00 & \multirow{2}{*}{$12 / 100$} \\
\hline P14. Non-structural elements & 0 & 5 & 20 & 50 & 0.75 & \\
\hline
\end{tabular}

\section{Vulnerability assessment of the Historical Center of Leiria}

\subsection{Assessment of parameters}

The compilation of the database and analysis of the parameters yields the parameter class distribution shown in Figure 7. Of these, P1, P2, P7, and P12 were found to be the most influential and given a weight of 1.5 or greater (Table 2). Parameters P3, P11, and P13 are also notable with weights of 1.0; P1, $\mathrm{P} 2, \mathrm{P} 3, \mathrm{P} 11, \mathrm{P} 12$, and $\mathrm{P} 13$ are the target of the retrofitting strategies presented in Section 6 . The position of a building within its aggregate (P7) is fixed and thus unaffected by retrofitting.

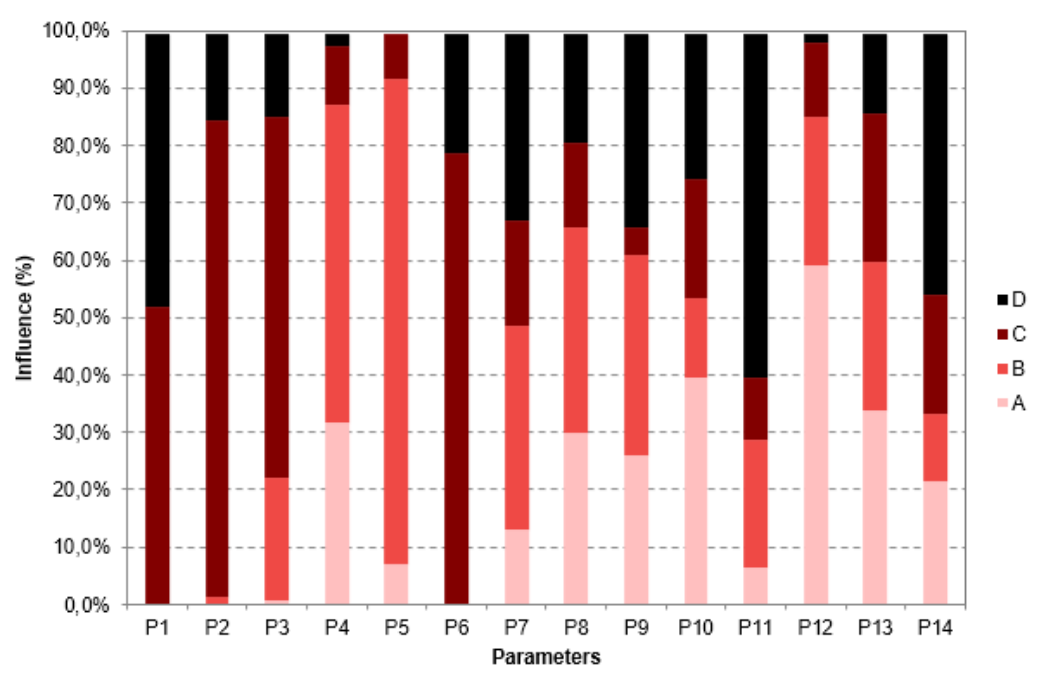

Figure 7. Vulnerability class distribution of each parameter 


\subsection{Parameter confidence factors}

207 The inherent uncertainty of the parameters necessitates an evaluation of the confidence in the data and the error accumulated during the gathering procedure. The propagation of error should be considered when evaluating the vulnerability index values. The present work attributed confidence classes to the parameters according to Vicente (2008), defined on the basis of the quality of the information gathered. A quantitative range of uncertainty from $0 \%$, total confidence, to $100 \%$, total uncertainty, was assigned to each confidence level listed in Table 3.

Two approaches were used for the uncertainty grade computation: an assumption based on expert opinion when the evaluation of a specific parameter consisted of a single data type or of a simplified assessment (P2, P5, P7, P8, P10, P13 and P14); or a combination of the uncertainty grades associated with the data used (P1, P3, P4, P6, P11 and P12). Thus, the factors applied as uncertainty levels can also be considered as an estimation of the error accumulated during data recording and assumption. A global confidence level for a single building cannot be computed because a summation would lead to overlapping sources of uncertainty (i.e. the presence of tie rods influences both parameters P1 and P12). Therefore, only the confidence levels related to a single parameter are provided. Still the results of this methodology can be used to discuss the reliability of the method applied. Table 3 presents the mean confidence classes calculated for each parameter with the associated graph shown in Figure 8.

Table 3. Average confidence classes for each parameter

\begin{tabular}{cccc}
\hline Parameter & Strategy & Average uncertainty & Average confidence class \\
\hline P1 & Combined & $38.2 \%$ & $\mathrm{M}$ \\
\hline P2 & Assigned & - & $\mathrm{M}$ \\
\hline P3 & Combined & $25.0 \%$ & $\mathrm{HM}$ \\
\hline P4 & Combined & $14.8 \%$ & $\mathrm{H}$ \\
\hline P5 & Assigned & - & $\mathrm{H}$ \\
\hline P6 & Combined & $36.9 \%$ & $\mathrm{M}$ \\
\hline P7 & Assigned & - & $\mathrm{H}$ \\
\hline P8 & Assigned & - & $\mathrm{ML}$ \\
\hline P9 & Assigned & - & $\mathrm{ML}$ \\
\hline P10 & Assigned & - & $\mathrm{H}$ \\
\hline P11 & Combined & $24.8 \%$ & $\mathrm{HM}$ \\
\hline P12 & Combined & $31.5 \%$ & $\mathrm{M}$ \\
\hline P13 & Assigned & - & $\mathrm{M}$ \\
\hline P14 & Assigned & - & $\mathrm{H}$ \\
\hline
\end{tabular}

High (H), High-Medium (HM), Medium (M), Medium-Low (ML), Low (L), Low-Absent (LA) and Absent (A)

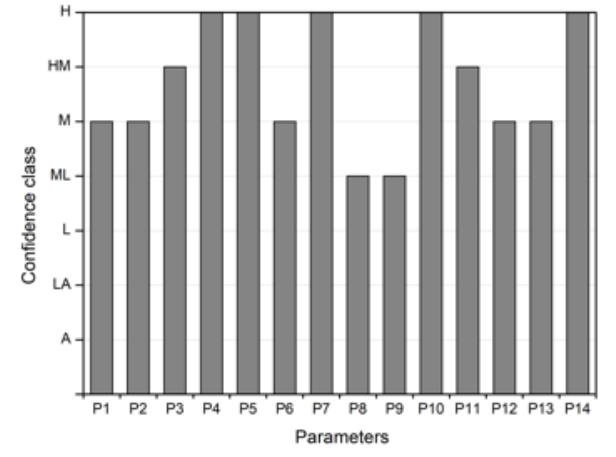

Figure 8. Bar chart distribution of the average confidence class for each parameter

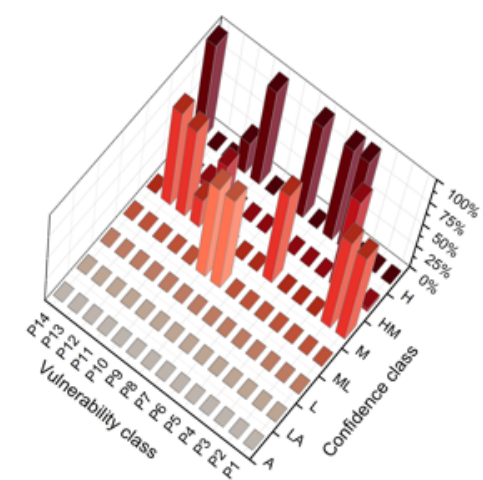

Figure 9. Matrix distribution of the confidence class for each parameter 
According to these calculations, the method used for the present work takes advantage of a medium confidence level with some parameters characterized by a high confidence class, generally those with a directly applied class or that express only dimensional features of the buildings.

228 In conclusion, the strategies used to evaluate the uncertainties of the vulnerability index method are a proposal for a starting point to include uncertainty and error propagation in large-scale vulnerability assessment methods. However, the confidence level factors need an appropriate formulation based on probabilistic studies that goes beyond the scope of this work. Figure 9 illustrates the distribution of the uncertainties affecting this work.

\subsection{Seismic vulnerability assessment}

The vulnerability assessment described in Section 4 was applied to 153 buildings and yielded a mean seismic vulnerability index value, $I_{v \text {,mean }}$, of 41.57 . The minimum value of the vulnerability index was 16.83 and the maximum was 82.67 . The associated standard deviation, $\sigma_{1 v}$, is 12.93 . The KolmogorovSmirnov normality test (Frank J. Massey Jr. 1951) confirmed that at the 0.05 significance level, the data was significantly drawn from a normally distributed population with a p-value of 0.148 . Figure 10 shows the histogram and the best-fit normal distribution curve resulting from the assessment. The buildings' conservation status ranges from good condition to ruin, and a good distribution of the $I_{v}$ values can be observed in the plots in Figure 11 (a). This distribution was mapped in GIS software to show the spatial relationship of the vulnerability index values in the study area (Figure 11).

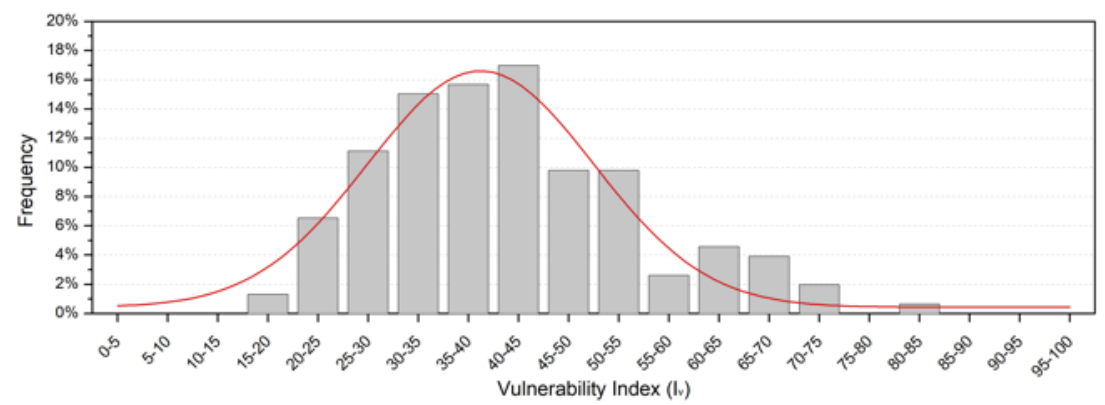

Figure 10. Vulnerability Index distribution of the building stock: histogram and best-fit normal distribution curve

The reliability of the method is demonstrated by the correlation between the most vulnerable buildings identified by visual inspection (P13) and those with high $I_{v}$ values. The corner and row end buildings are generally more vulnerable than those located in the middle of the block, a phenomenon observed by Vicente et al. (2015) and demonstrated by Figure 11. This is due to the aggregate position effect and the interaction with adjacent buildings during a seismic event that may cause additional damage through the floor hammering or roof misalignments. 


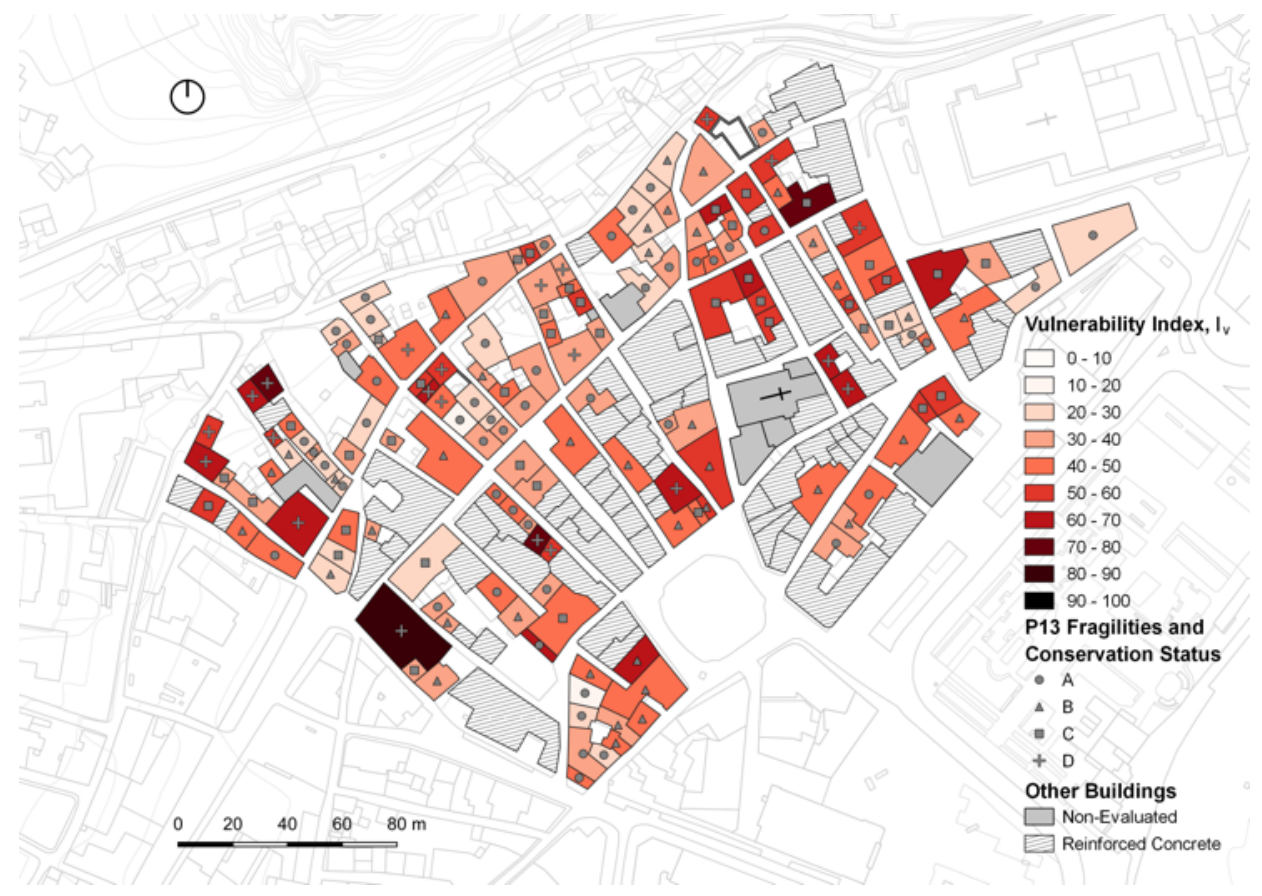

(a)

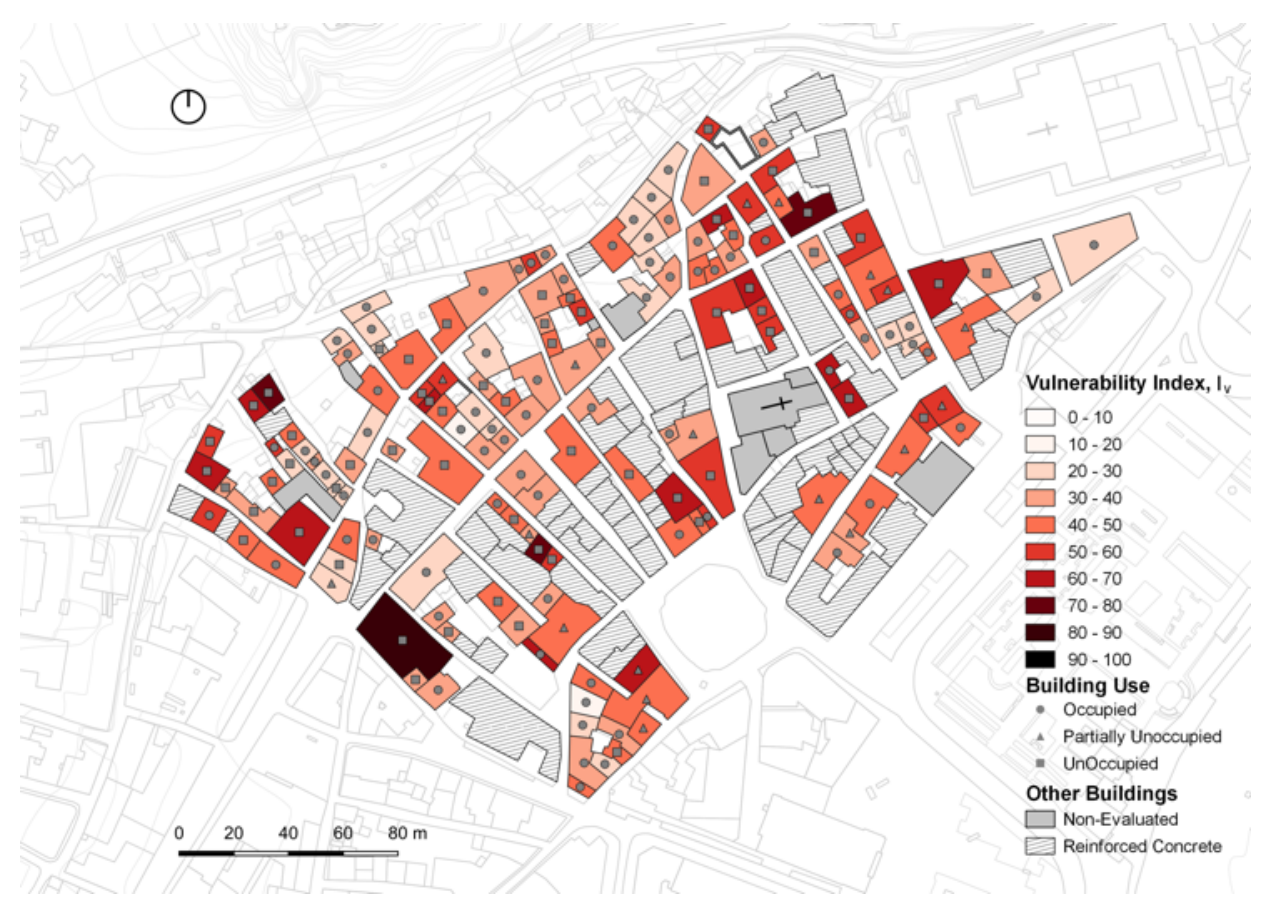

(b)

Figure 11. Vulnerability index values shown with: (a) class distribution of parameter P13, fragilities and conservation status; and (b) state of use of buildings.

254 Additionally, Figure 11 (b) shows that unoccupied or partially occupied buildings generally have 255 higher vulnerability index values than occupied ones. This is due to lack of maintenance resulting from the state of abandonment. 


\subsection{Damage grade distributions}

\subsubsection{Mean damage grades}

In an effort to quantify the damage likely to by incurred by buildings in the historic city center of Leiria for a seismic event of a given intensity, mean damage grades $\left(\mu_{D}\right)$ were calculated in accordance with the approach proposed by Bernardini et al. with the macroseismic intensities defined by EMS - 98 (Bernardini et al. 2007; Grünthal 1998). The damage grades are calculated using the seismic hazard in terms of the macroseismic intensity, the vulnerability index, see Equation (1), and a ductility factor corresponding to the building typology according to Equation (2):

$$
\mu_{D}=2.5+\left[3 \times \tanh \left(\frac{I+6.25 \times V-12.7}{Q}\right)\right] \times f(V, I) ; 0 \leq \mu_{D} \leq 5
$$

where I is the seismic hazard according to EMS-98, V is the vulnerability index, and Q is the ductility factor. Bernardini et al. (2007) found that the ductility factor of $Q=3.0$ was acceptable for masonry buildings similar to those found in Leiria, so the same factor was adopted for this case study. The calculated damage grades range from 0 to 5 , where 5 represents the worst possible damage grade.

Equation (3) relates the vulnerability index $\left(I_{v}\right)$ described in Section 5.2 to the vulnerability index $(V)$ used in the macroseismic method and in determining the mean damage grades, and $f(V, I)$ is a function of the vulnerability and intensity that pertains to trends associated with lower vulnerability grades ( $\mathrm{I}_{\mathrm{EMS}}$ ${ }_{98}=\mathrm{V}$ or VI), see Equation (4) (Vicente et al. 2011).

$$
\begin{aligned}
V & =0.592+0.0057 \times I_{v} \\
f(V, I) & = \begin{cases}e^{V / 2 \times(I-7)} & I \leq 7 \\
1 & I>7\end{cases}
\end{aligned}
$$

Vulnerability curves are plotted in Figure 12 that show the expected mean damage grade for events with a range of macroseismic intensities given the mean value of the vulnerability index $\left(I_{v, \text { mean }}\right)$ and upper and lower bound ranges $\left(I_{v, \text { mean }} \pm 1 \sigma_{I_{v}}, I_{v \text {,mean }} \pm 2 \sigma_{I_{v}}\right)$ found for Leiria.

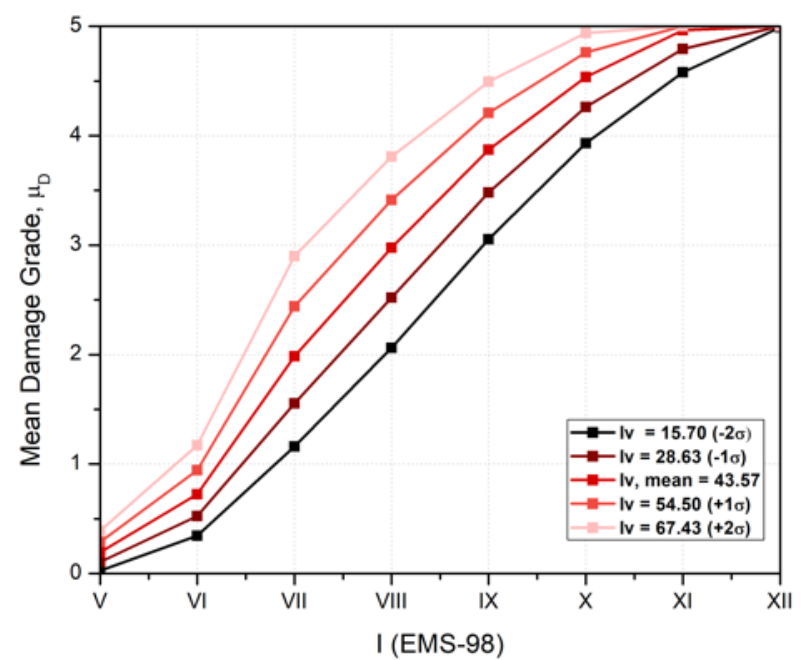

Figure 12. Mean damage grade curves for characteristic values of the vulnerability index

277 While the vulnerability curve is able to show the mean damage grade for the average $\left(I_{v, \text { mean }}\right)$ building found in Leiria's city center, by using the GIS tool the mean damage grades for every building can be 
visualized in their actual location on the map. Figure 13 shows the distribution of the mean damage

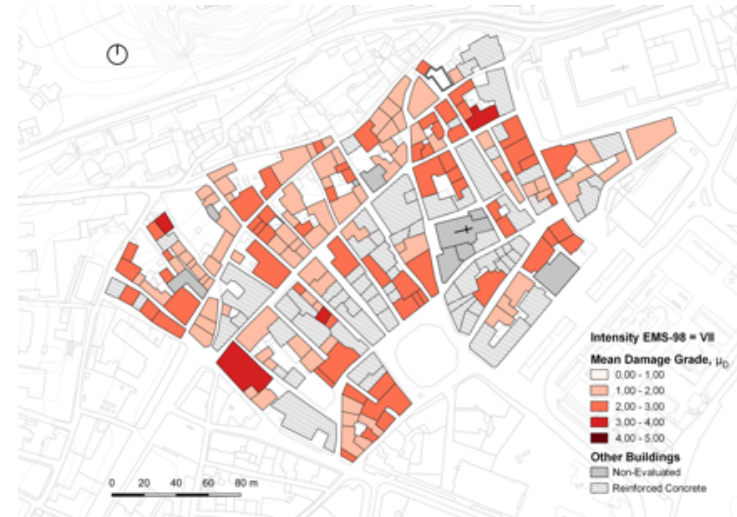

(a)

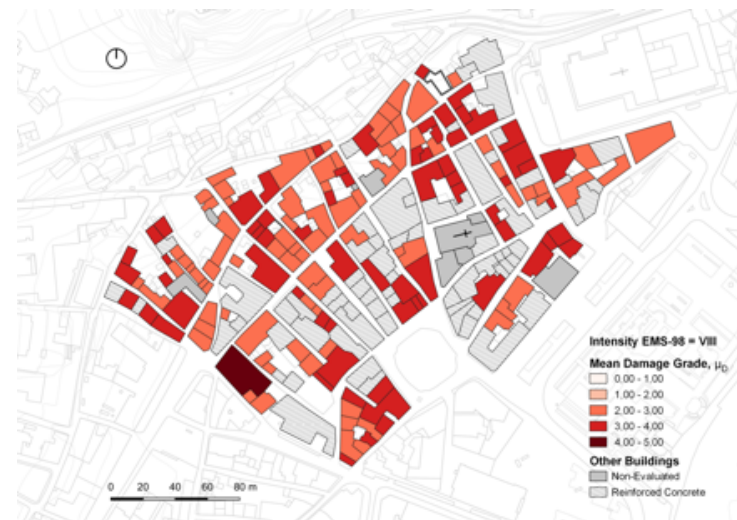

(b)

\subsubsection{Discrete damage grades}

The mean damage grades calculated for each building can be converted to discrete damage grades $\left(D_{k}\right.$, $k \in[0 ; 5]$ ) defined in EMS - 98 (Grünthal 1998). The discrete damage grade represents the cost of returning a building to its original condition before the earthquake occurred. To perform the conversion a probabilistic distribution based on the discretization of a beta distribution defined between 0 and 5 is assumed. The correlation proposed by Bramerini et al. (1995), which can be approximated by the Equation (5), was used in this case study. Damage factors $(D F)$ defined for each discrete damage grade are used to relate the discrete damage grade to the mean damage grade according to the approach proposed by Maio et al. (2019).

$$
\mu_{D}=5 D F^{0.52}
$$

292

These discrete damage grades can be applied to the vulnerability indices in order to calculate fragility curves and estimations of loss to describe the effect of seismic action on the historical center of Leiria, which are presented in the following sections.

\subsection{Fragility curves}

Fragility curves can be plotted in order to visualize the probability of reaching or exceeding the discrete damage grades described in the previous section for a range of macroseismic intensities. A beta cumulative density function is used to define the cumulative probability of reaching or exceeding a certain damage state based on the damage recorded in the database (Giovanizzi 2005).The discrete probability, $P\left(D_{k}\right)=d$, can be derived from the difference of cumulative probabilities, $P_{D}\left[D_{i} \geq d\right]$, and is described by the following Equation (6) (Ferreira et al. 2013):

$$
P\left(D_{k}=d\right)=P_{D}\left[D_{k} \geq d\right]-P_{D}\left[D_{k+1} \geq d\right]
$$

Figure 14 shows the fragility curves plotted as continuous probability functions for the mean vulnerability index value $\left(I_{v, \text { mean }}=41.57\right)$. 


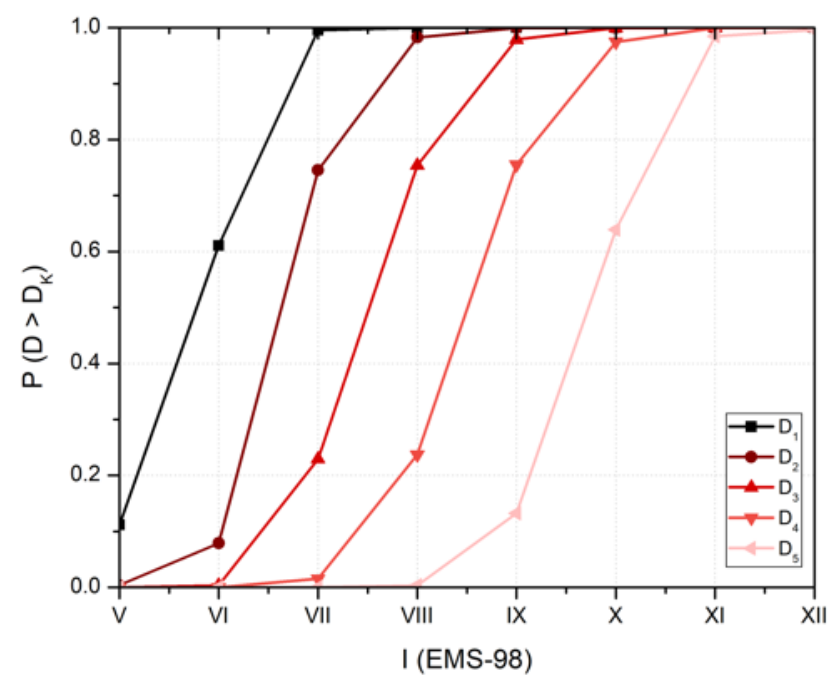

Figure 14 . Fragility curve depicting the probability of reaching or exceeding discrete damage grades $\mathrm{D}_{1}-\mathrm{D}_{5}$

\section{Retrofitting strategies}

The analysis shows that structural deficiencies and deterioration processes are the factors having the most influence over the final $I_{v}$ value. The potential vulnerabilities should be corrected by performing minimum interventions that respect historical and cultural values, and economic efficiency. Although interventions should be based on an assessment of a particular structure, the "packaging" strategy has been recognized as an effective method for improving the seismic performance of unreinforced stone masonry buildings at an urban scale (Bothara and Brzev 2011; Penna 2014; Tomaževič 1999). In the present study, five retrofitting solutions for increasing invasiveness and cost, S1 to S5, are proposed and grouped into two incremental packages: RP1 and RP2 (Figure 15). They are based on design recommendations from the Civil Engineering Regional Laboratory of Azores (LREC) in cooperation with professionals and technicians made after the 1998 earthquake (Cansado et al. 1998; Costa et al. 2008; Oliveira et al. 1990). The cost evaluation refers to the retrofitting strategies already proposed by Ferreira et al. (2017b), based on the detailed structural design projects contained in a database related to the rehabilitation process of the Faial island in 1998 which were considered representative of the traditional Azorean buildings.

The first retrofitting package, RP1, has an estimated cost of $35 € / \mathrm{m}^{2}$, referring to the Ferreira et al. (2017 b) prediction, and consists of four interventions aimed at improving: wall-to-wall connection by tie-rods applied at floor or roof level (S1), in-plane stiffness of diaphragms through the application of diagonal bracings and new layer of timber planks (S2), wall-to-floor connection by perimeter steel beams properly anchored to the stone masonry walls (S3), and wall-to-roof connection by means of tie-rods that correct any potential horizontal thrust (S4). The second package RP2 has an estimated cost of 185 $€ / \mathrm{m}^{2}$ and includes all the retrofitting solutions of RP1 complemented by the jacketing technique of applying a reinforced plaster layer connected to the existing masonry walls by transversal tying (S5). A detailed description of each intervention is given by Ferreira et al. (2017b), Cansado et al. (1998), Costa (2002) and Bothara and Brzev (2011). 


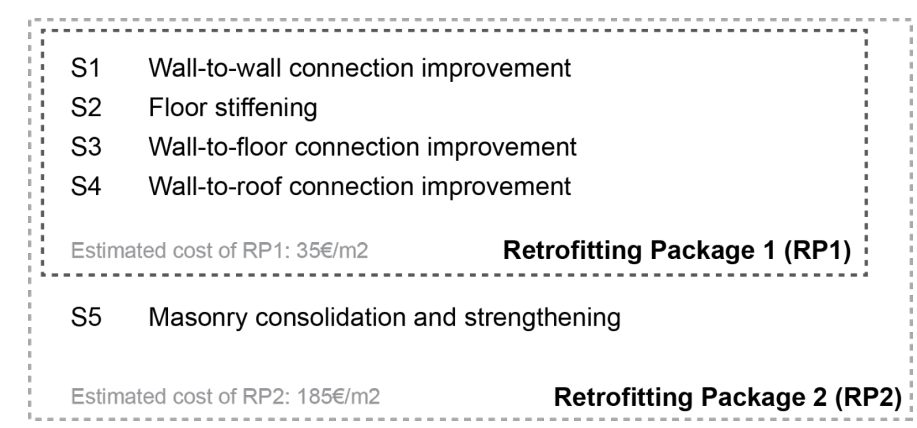

Figure 15. Seismic retrofitting solutions adopted

\subsection{Vulnerability index updating}

334 The effectiveness of the application of a certain retrofitting package was evaluated by updating the vulnerability index values according to the parameters affected by the retrofitting technique. RP1 and RP2 decrease the vulnerability index values $I_{v}$ by upgrading the vulnerability classes $C_{\mathrm{vi}}$ of parameters P1, P11, P12 and P2, P3, P13 respectively (Table 4). The application of RP1 yields a maximum improvement to vulnerability class B for P1, since class A relates to designed masonry structures, and to class A for P11. In the present case, parameter P12 is not upgraded because its evaluation depends on expert assumptions that led to the maximum class A by default. The buildings that are grouped in the lower classes have other deficiencies and thus improving the class may not be conservative.

Table 4. Influence of each retrofitting solution over the vulnerability index value $I_{v}$

\begin{tabular}{lcccccc}
\hline Retrofitting solution & P1 & P2 & P3 & P11 & P12 & P13 \\
\hline S1 & $\checkmark$ & & & & & \\
\hline S2 & $\checkmark$ & & & $\checkmark$ & & \\
\hline S3 & $\checkmark$ & & & $\checkmark$ & & \\
\hline S4 & $\checkmark$ & & & & $\checkmark$ & \\
\hline S5 & $\checkmark$ & $\checkmark$ & $\checkmark$ & & & $\checkmark$ \\
\hline Maximum class & B & A & $\tau$ & A & - & A \\
\hline
\end{tabular}

The jacketing technique in RP2 influences the vulnerability class of P2, which improves to class A after the intervention (Table 4). The conventional shear strength of masonry walls (P3) is updated as well. Since the types and qualities of masonry walls are characterized and compared with those in the Italian code, its method is applied. It allows an increase of the mechanical properties of masonry subjected to intervention by multiplying them with coefficients (Circolare 21 gennaio 2019 n. 7 C.S.LL.PP. 2019). Thus, the vulnerability class of P3 is updated considering the modified shear strength. The implementation of both RP1 and RP2 improve the global conservation state leading to the maximum class A for P13, Table 4.

Unlike past case studies (Ferreira et al. 2017b), the retrofitting strategies of this work were not applied to the whole building stock of Leiria's city center but only to the most vulnerable building, which are those with a mean damage grade above 3 for an event of macroseismic intensity VIII, which is representative of the seismic hazard in Leiria. This approach is preferable because of its economic affordability and because it requires minimum intervention with an acceptable degree of efficiency. As 
a result, 69 constructions (45\%) were subjected to RP1, Figure 16 (a). The updated mean damage grade was still higher than 3 after the RP1 interventions for 21 buildings (13.7\%) out of the original 69. RP2 was therefore applied to these 21 buildings to further reduce their mean damage grades, Figure 16 (b). Finally, the total cost for the application of RP1 was computed as $€ 862,330.70$ and the total cost for the application of RP2 was found to be $€ 1,215,111.00$. Bearing in mind that the given amounts are representative and do not correspond to the real expenses that incurred by application, these results are useful to evaluate the cost-benefit balance that will be discussed in the following sections.

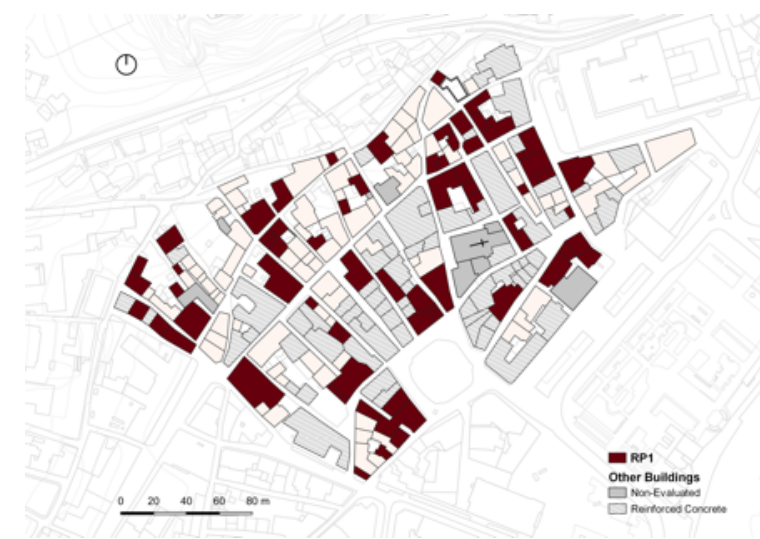

(a)

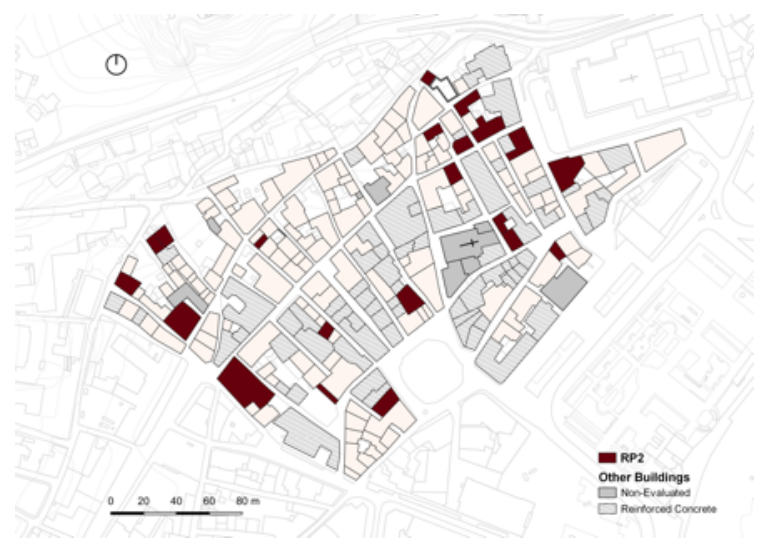

(b)

Figure 16. Location of the building intervened with the RP1 (a) and the RP2 (b)

In Figure 17 the highlighted parameters are those affected by the application of each retrofitting package. Table 5 shows the mean vulnerability index $I_{v}$ and standard deviation $\sigma_{1 v}$ before (BR) and after (RP1 and RP2) retrofitting. Through the application of RP1, the initial mean value of seismic vulnerability index, $I_{v}$, decreases from 41.57 to 34.05 (18.1\%). Finally, by applying RP2, this reduction increases around $26.7 \%$. Figure 18 shows RP1 and RP2 best-fit normal distribution curves shifted and shrunk around the updated mean $I_{v}$ values as a result of the reduction in the mean vulnerability index and standard deviation values, Table 5.

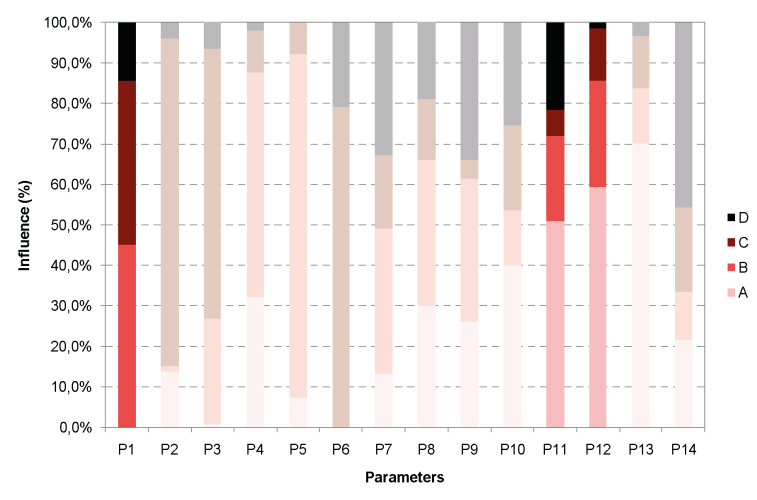

(a)

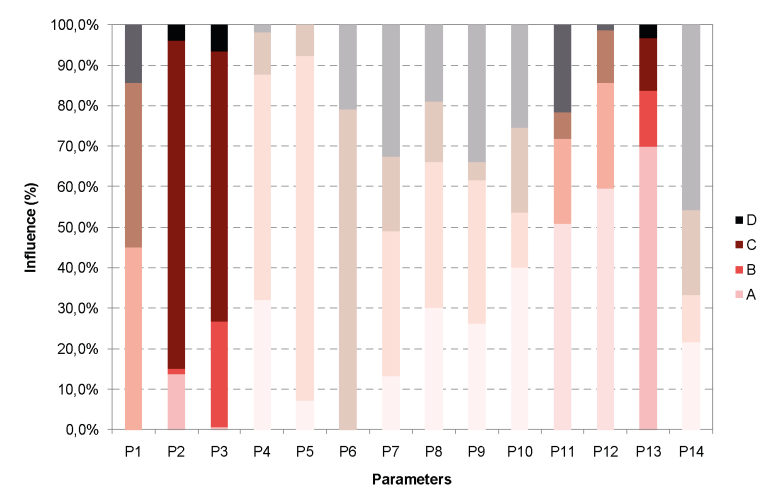

(b)

Figure 17. Vulnerability class distribution after the application of RP1 to the selected 69 buildings (a) and of the RP2 to the selected 21 buildings (b) 
Table 5. Influence of each retrofitting solution over the $\mathrm{I}_{\mathrm{v}}$ and standard deviation $\sigma_{\mathrm{IV}}$

\begin{tabular}{ccccc}
\hline $\begin{array}{c}\text { Building } \\
\text { condition }\end{array}$ & $\mathbf{I}_{\mathbf{v}, \text { mean }}$ & $\begin{array}{c}\mathbf{I}_{\mathbf{v}, \text { mean }} \\
\text { reduction }\end{array}$ & $\boldsymbol{\sigma}_{\mathrm{Iv}}$ & $\begin{array}{c}\boldsymbol{\sigma}_{\mathrm{Iv}} \\
\text { reduction }\end{array}$ \\
\hline BR & 41.57 & - & 12.93 & - \\
\hline RP1 & 34.05 & $18.1 \%$ & 8.11 & $37.3 \%$ \\
\hline RP2 & 30.49 & $26.7 \%$ & 6.14 & $52.5 \%$ \\
\hline
\end{tabular}

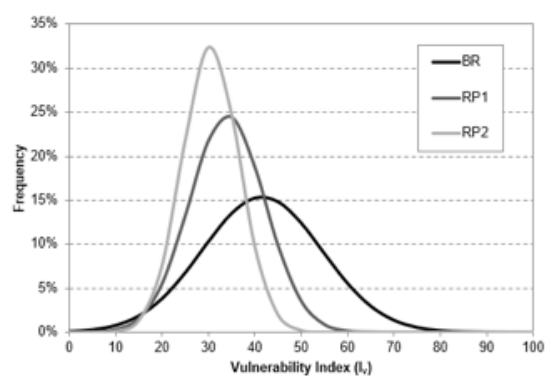

Figure 18. Best-fit normal distribution curve of Iv before and after retrofitting

\section{Loss estimation}

Loss estimation has the potential to play a key role in effective loss mitigation by applying retrofitting strategies. A cost-benefit analysis based on quantitative data about the population and building stock vulnerability allows municipalities to make informed decisions regarding risk prevention (D'ayala et al. 1997) as well as the type and the extent of retrofitting strategies to adopt. Moreover, a cost-benefit analysis based on loss estimation allows for evaluation of the effectiveness of the measures taken.

Estimations of loss were calculated based on three different scenarios: before retrofitting (BR), after the application of the Retrofitting Package 1 (RP1), and after the application of the Retrofitting Package 2 (RP2). The literature presents many strategies for loss estimations based on the probabilities of occurrence of certain damage scenarios. For this approach, the loss will be estimated through the use of the characteristic vulnerability indices $\left(I_{v}, I_{v \text {, mean }} \pm 1 \sigma_{I_{v}}, I_{v \text {,mean }} \pm 2 \sigma_{I_{v}}\right)$ and the GIS tool.

The effectiveness of the damage estimation models ultimately relies on the accuracy of the damage grades presented in Section 5.4.2. Thus, it is dependent on the probability of meeting or exceeding a certain damage grade and other loss phenomena (i.e., collapse, homelessness, death and severe injury, etc.) (Ferreira 2010).

\subsection{Collapsed and unusable buildings}

The estimation of probable losses in terms of collapsed and unusable buildings were calculated following the approach proposed by Bramerini et al. (1995) and adopted by the Italian Servizio Sismico Nazionale (SSN). The probability of a building to meet or exceed a certain damage grade is statistically weighted and summed to obtain the probabilities of collapse (Equation (7)) and unusability (Equation (8)), where the weighting factors applied were taken from values found in similar Portuguese case studies (Ferreira et al. 2013).

$$
\begin{gathered}
P_{\text {collapse }}=P\left(D_{5}\right) \\
P_{\text {unusable }}=P\left(D_{3}\right) \times W_{e i, 3}+P\left(D_{4}\right) \times W_{e i, 4}
\end{gathered}
$$

According to the average vulnerability index values, the probability curves for collapsed and unusable buildings can be plotted for the BR scenario. Figure 19 (b) demonstrates that with increasing size of seismic events, the number of unusable buildings increases up to a maximum and then begins to decrease as the increase in the number of collapsed buildings continues to increase, Figure 19 (a). Using the GIS tool, these results can be visualized across the study area by plotting each calculated probability with the associated building code. Figure 20 (a) and (b) show the probability of unusability across the historical center of Leiria combined with the probability of collapse. 


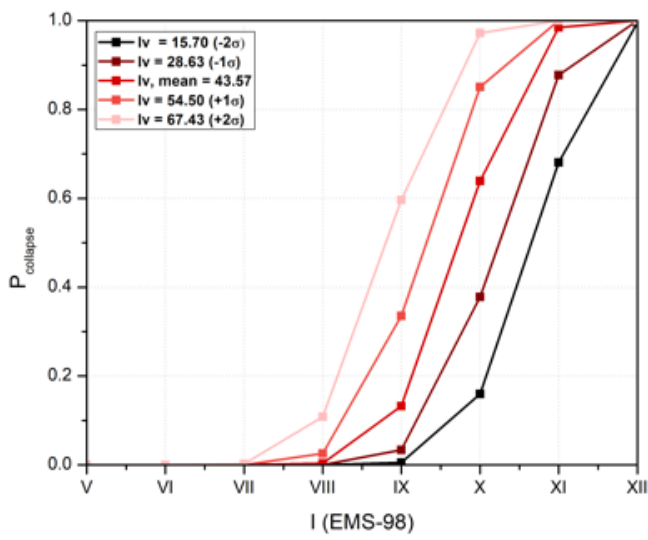

(a)

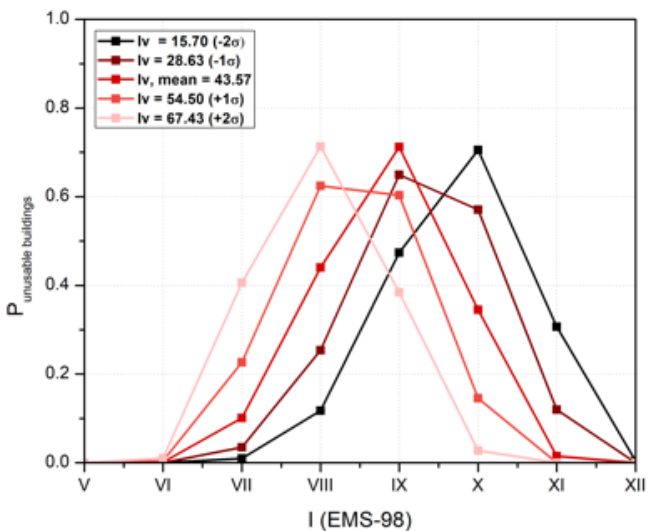

(b)

Figure 19. Probability of collapsed (a) and unusable (b) buildings for characteristic vulnerability index values

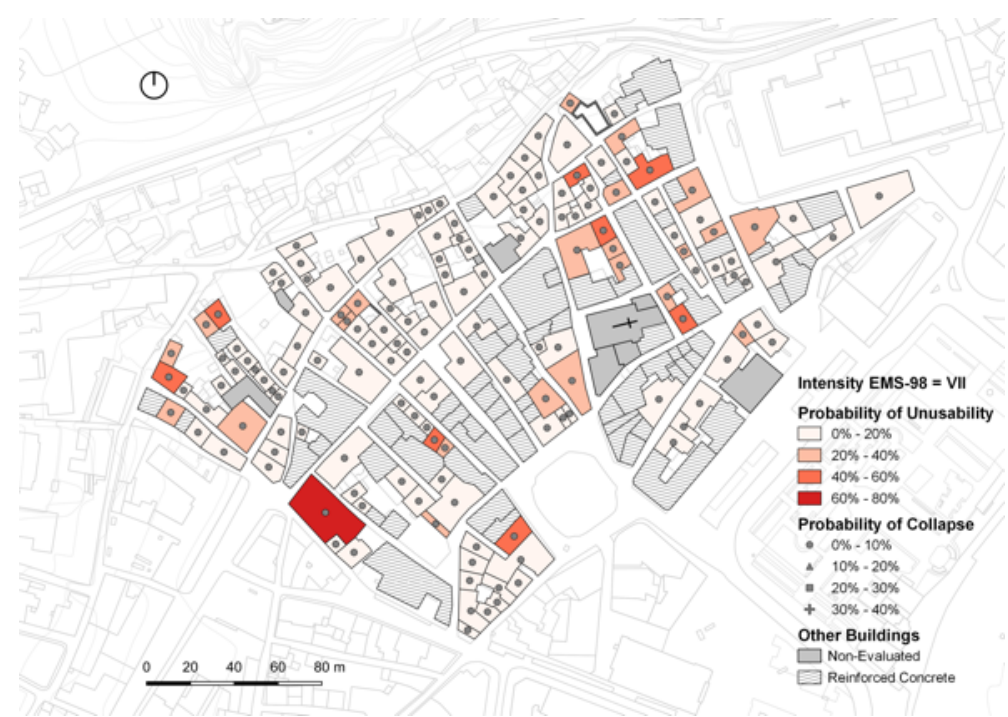

(a)

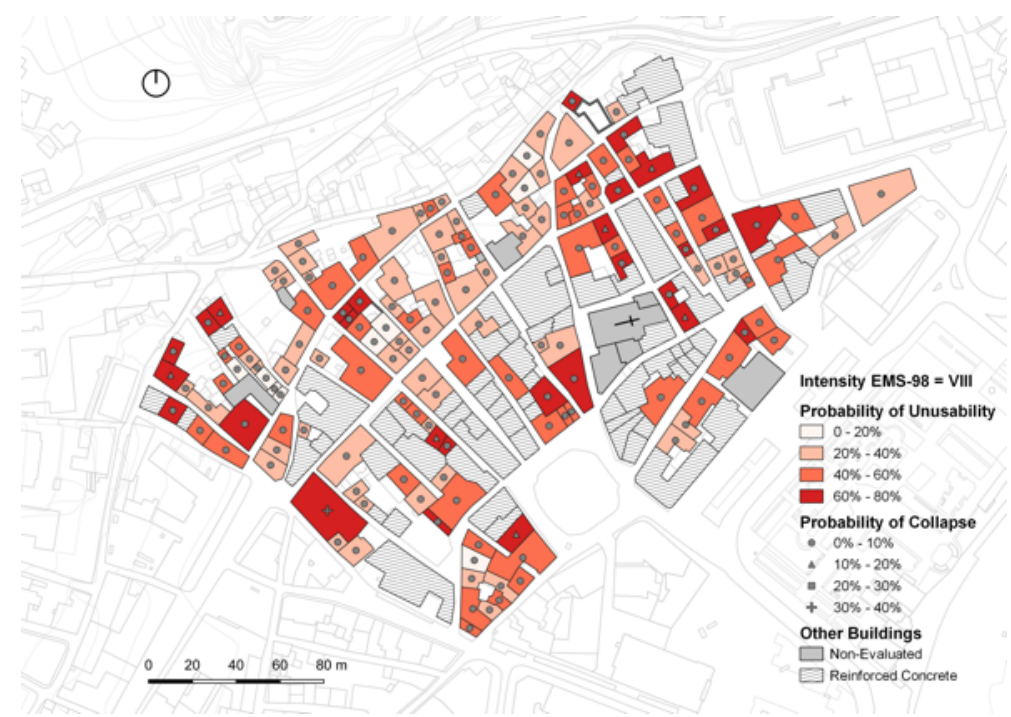

(b)

Figure 20. Map of the probabilities of unusability and collapse for an event of seismic intensity $\mathrm{I}_{\mathrm{EMS}-98}=$ VII (a) and $\mathrm{I}_{\mathrm{EMS}-98}=$ VIII (b) 
The number of collapsed buildings becomes relevant when the earthquake intensity exceeds XI, which is larger than expected in Leiria. However, this number can be reduced by $50 \%$ with the application of the RP1 and by over $70 \%$ for RP 2 . The number of unusable buildings undergoes a smaller improvement after retrofitting but is relevant for lower intensities. The number of unusable buildings after the application of the retrofitting techniques exhibits a maximum improvement for intensity VIII (Figure 21) and, after reaching the peak value becomes larger than in the unreinforced condition (BR) because the reinforcement strategy prevents more buildings from collapsing. In the unlikely occurrence of a seismic event with intensity greater than IX, more buildings are unusable in the strengthened scenarios and fewer collapse.

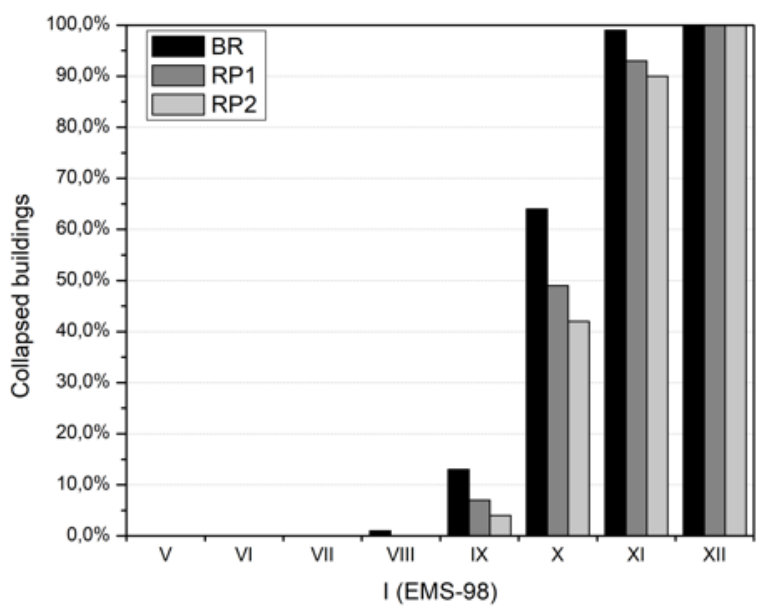

(a)

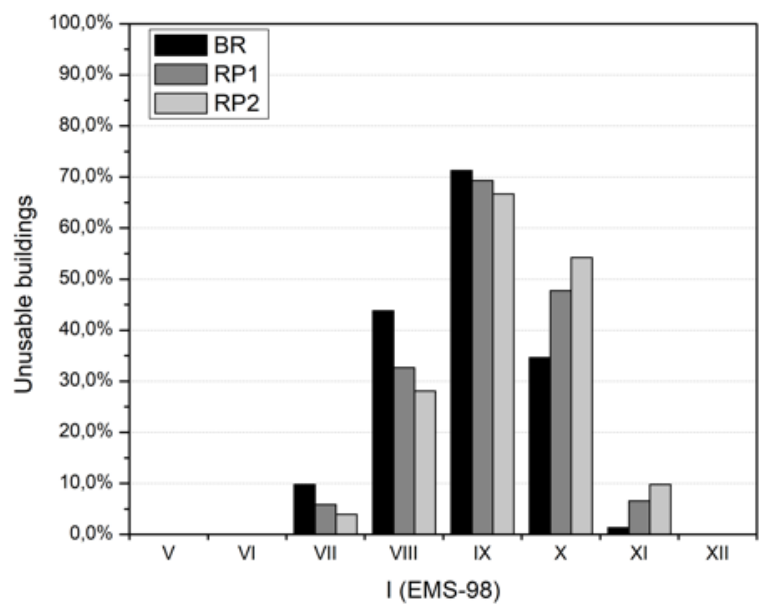

(b)

Figure 21. Probability of collapsed buildings (a) and unusable buildings (b) for the different building conditions analyzed

\subsection{Human casualties}

The approach from SSN was also used to evaluate probabilities of human casualties (dead or severely injured) and homelessness in Leiria following a seismic event. Ferreira et al. (2013) defines the rate of casualty as $30 \%$ of the residents in collapsed or unusable buildings, and the remaining residents of these buildings as homeless. The following Equations (9) and (10) were used to determine the probabilities associated with casualties and homelessness (Ferreira et al. 2013):

$$
\begin{gathered}
P_{\text {death }}=0.3 \times P\left(D_{5}\right) \\
P_{\text {homeless }}=P\left(D_{3}\right) \times W_{e i, 3}+P\left(D_{4}\right) \times W_{e i, 4}+0.7 \times D_{5}
\end{gathered}
$$

An estimation of the number of resulting casualties and homeless people can be calculated according to the demographic data given by the census (Section 2.1) (Table 6 and Table 7). Figure 22 plots the probabilities of casualties and homeless people for the characteristic vulnerability index values $\left(I_{v}\right.$, $I_{v \text {,mean }} \pm 1 \sigma_{I_{v}}, I_{v \text {,mean }} \pm 2 \sigma_{I_{v}}$ ) in the BR condition. At lower intensity events, the population is scarcely affected by the earthquake in terms of deaths or injuries. Above intensity IX, the entire population falls into one of these two categories, reaching a probability of $28-35 \%$ of human casualties and $70-80 \%$ of homeless people. Figure 22 (b) shows the probability of homelessness reaches a maximum of about $80 \%$ of the population and then decreases as the death toll arises. 


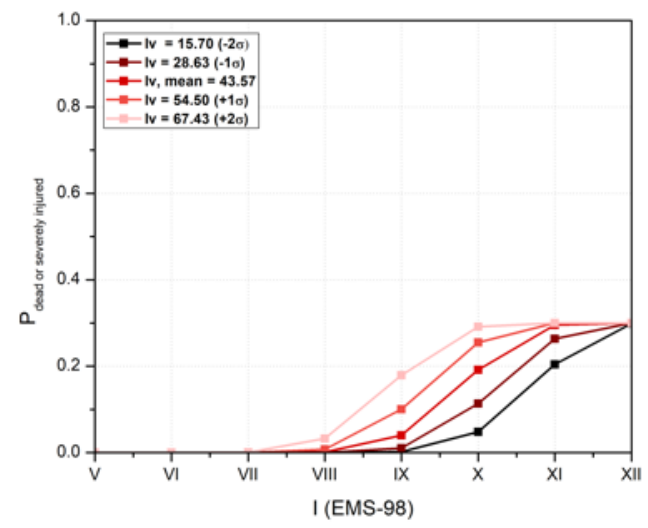

(a)

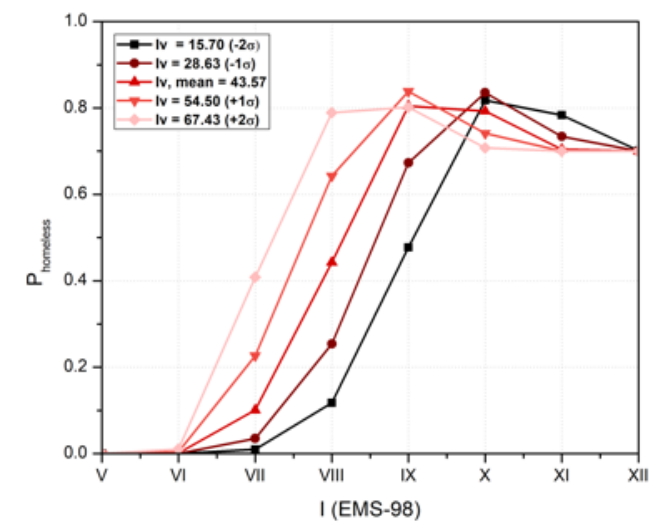

(b)

Figure 22. Probabilities of human casualties (a) and homeless (b) for the characteristic vulnerability index values over a range of seismic intensities

Table 6. Estimation of the number of dead or severely injured people

\begin{tabular}{|c|c|c|c|c|c|c|c|c|}
\hline & \multicolumn{8}{|c|}{ Intensity, I I EMS-98 } \\
\hline & $\mathbf{V}$ & VI & VII & VIII & IX & $\mathbf{X}$ & XI & XII \\
\hline BR & 0 & 0 & 0 & 0 & $13(4.1 \%)$ & $60(19.0 \%)$ & $93(29.5 \%)$ & $94(29.8 \%)$ \\
\hline RP1 & 0 & 0 & 0 & 0 & $6(1.9 \%)$ & $46(14.6 \%)$ & $88(27.9 \%)$ & $94(29.8 \%)$ \\
\hline RP2 & 0 & 0 & 0 & 0 & $4(1.3 \%)$ & $39(12.4 \%)$ & $85(27.0 \%)$ & $94(29.8 \%)$ \\
\hline
\end{tabular}

Table 7. Estimation of the number of homeless people

\begin{tabular}{ccccccccc}
\hline \multicolumn{7}{c}{ Intensity, IEMS-98 } \\
\hline & V & VI & VII & VIII & IX & X & XI & XII \\
\hline BR & 0 & 0 & $32(10.2 \%)$ & $139(44.1 \%)$ & $254(80.6 \%)$ & $250(79.4 \%)$ & $222(70.5 \%)$ & $221(70.2 \%)$ \\
\hline RP1 & 0 & 0 & $18(5.7 \%)$ & $103(32.7 \%)$ & $233(74.0 \%)$ & $259(82.2 \%)$ & $226(71.7 \%)$ & $221(70.2 \%)$ \\
\hline RP2 & 0 & 0 & $13(4.1 \%)$ & $88(27.9 \%)$ & $220(69.8 \%)$ & $262(83.2 \%)$ & $229(72.7 \%)$ & $221(70.2 \%)$ \\
\hline
\end{tabular}

Figure 23 demonstrates the effectiveness application of the retrofitting strategies on the human casualties. Due to the small number of people registered as living in the city center, a probability of having casualties (Figure 23 (a)) occurs only above intensity IX. However, if the maximum intensities (from IX to XII) are considered, a decreasing trend can be seen after applying the RP1 and RP2 up to intensity XI. After that the probability remains constant ( $30 \%$ for intensity XII) due to the destructiveness of the seismic event. The maximum variation can be observed for intensity $\mathrm{X}$ where the probability drops from $19 \%$ (BR) to $15 \%$ (RP1) and $12 \%$ (RP2). In terms of probability of homelessness, in Figure 23 (b), a decreasing trend can be seen up to seismic intensity IX due to a decrease in the number of collapsed buildings for the retrofitted scenarios. Then this trend reverses because there are more non-collapsed buildings after the retrofitting interventions. These outputs can be used for emergency planning by authorities and civil protection since they provide an estimation of the number of people that will need to be temporarily relocated. 


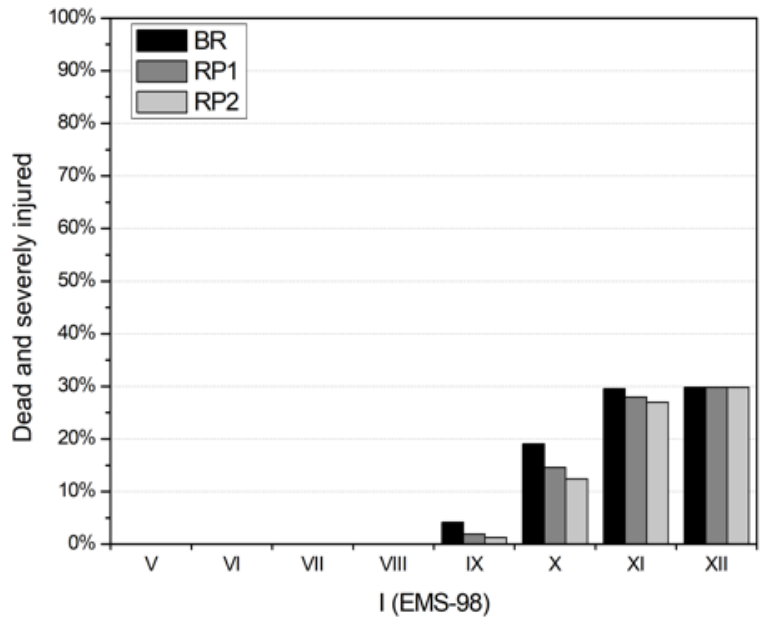

(a)

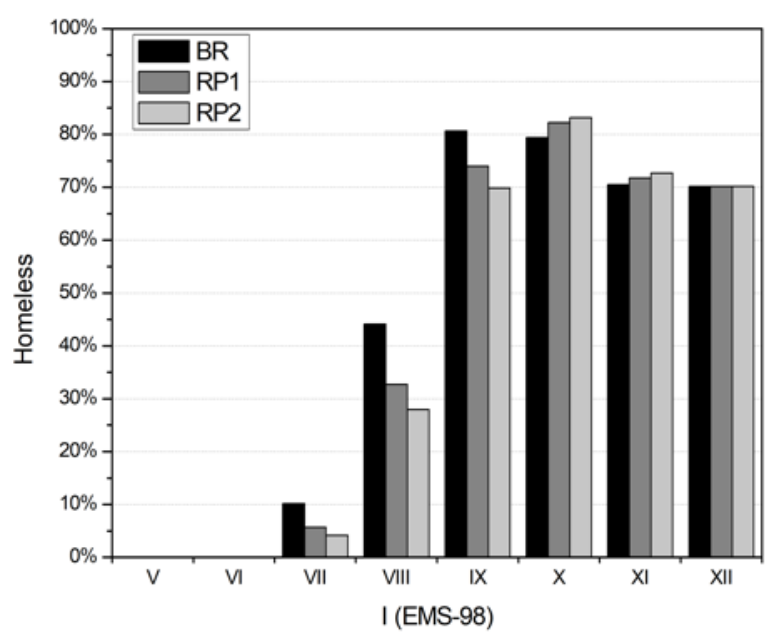

(b)

Figure 23. Probability of dead or severely injured (a) and homeless (b) people

\subsection{Economic balance}

The estimated damage is defined as the cost of repair required for a building following a seismic event. By analyzing post-earthquake damage data and current construction costs it is possible to correlate the costs of repairs with the damage grades. This work uses the correlation developed by Maio et al. (2019) in accordance with the damage observed in 1395 buildings due to the 1998 Azores earthquake. The cost of repair and replacement is correlated to the discrete damage grades with Equation (11) proposed by Ferreira et al. (2013) using the macro-seismic intensity $(I)$, discrete damage level $\left(P\left[R \mid D_{k}\right]\right)$ and the probability of reaching that damage condition given a certain vulnerability index $\left(P\left[D_{k} \mid I_{v}\right]\right)$.

$$
P[R \mid I]=\sum_{D_{k}=1}^{5} \sum_{I_{v}=0}^{100} P\left[R \mid D_{k}\right] \times P\left[D_{k} \mid I_{v}\right]
$$

While retrofitting an existing building may involve two or three times the initial investment of construction, repair and strengthening the same building after a seismic event may be four to eight times as expensive (Ferreira et al. 2017b). Moreover, the replacement of damaged or existing unsafe buildings by reconstruction should generally be avoided because of higher costs of reconstruction than those of strengthening or retrofitting actions, preservation and safeguarding of historical architecture and built heritage, and maintaining of functional, social and cultural environment (Ferreira et al. 2017b).

The economic losses are calculated singularly for each building and then summed (Table 8). In contrast, past studies have computed economic losses with respect to a mean vulnerability index value and total evaluated area of the building stock, likewise for the human losses and collapsed buildings (Ferreira et al. 2017b). The approach undertaken in this work can be considered valuable as the evaluation of economic loss for each building was possible. The economic balance can be considered the most powerful tool for evaluating the effectiveness of the retrofitting strategies considered, since it allows estimation of both the total savings obtained in terms of repair costs and replacement after a seismic event of a certain intensity and the payback of the investment undertaken (Table 9). 


\begin{tabular}{|c|c|c|c|c|c|c|c|c|}
\hline & $\mathbf{V}$ & VI & VII & VIII & IX & $\mathbf{X}$ & XI & XII \\
\hline RP1 & $0.14 \mathrm{M} €$ & $0.52 \mathrm{M} €$ & $5.12 \mathrm{M} €$ & $9.61 \mathrm{M} €$ & $9.31 \mathrm{M} €$ & $5.75 \mathrm{M} €$ & $1.29 \mathrm{M} €$ & - \\
\hline RP2 & $0.20 \mathrm{M} €$ & $0.75 \mathrm{M} €$ & $6.91 \mathrm{M} €$ & 13.98 M€ & 14.24 M€ & $9.28 \mathrm{M} €$ & $2.42 \mathrm{M} €$ & - \\
\hline
\end{tabular}

Table 9. Payback for each retrofitting packages applied (in millions of $€$ )

\begin{tabular}{|c|c|c|c|c|c|c|c|c|}
\hline & \multicolumn{8}{|c|}{ Intensity, IEMS-98 } \\
\hline & $\mathbf{v}$ & VI & VII & VIII & IX & $\mathbf{x}$ & $\mathbf{X I}$ & XII \\
\hline RP1 & - $0.72 \mathrm{M} €$ & - $0.34 \mathrm{M} €$ & $4.26 \mathrm{M} €$ & $8.75 \mathrm{M} €$ & $8.44 \mathrm{M} €$ & $4.89 \mathrm{M} €$ & $0.43 \mathrm{M} €$ & $-0.86 \mathrm{M} €$ \\
\hline RP2 & $-2.23 \mathrm{M} €$ & $-1.68 \mathrm{M} €$ & $4.48 \mathrm{M} €$ & $11.55 \mathrm{M} €$ & $11.81 \mathrm{M} €$ & $6.85 \mathrm{M} €$ & $-0.01 \mathrm{M} €$ & $-2.43 \mathrm{M} €$ \\
\hline
\end{tabular}

The application of the retrofitting strategy decreases the estimated economic losses for low intensity earthquakes $\left(\mathrm{I}_{\mathrm{EMS}-98}=\mathrm{VII}\right)$ from 13.27 M€ to $8.15 \mathrm{M} €$ for RP1 (reduction about 39\%) and to $6.36 \mathrm{M} €$ for RP2 (reduction about 52\%), see Figure 24. For higher intensities the repair costs of the retrofitted scenarios are equivalent to the initial repair costs of the BR situation, because these are unlikely situations, and total destruction is expected.

Considering the repair costs and the total cost of each retrofitting package, the seismic intensity range for which the application of the indicated retrofitting strategies is effective can be identified, Figure 25.

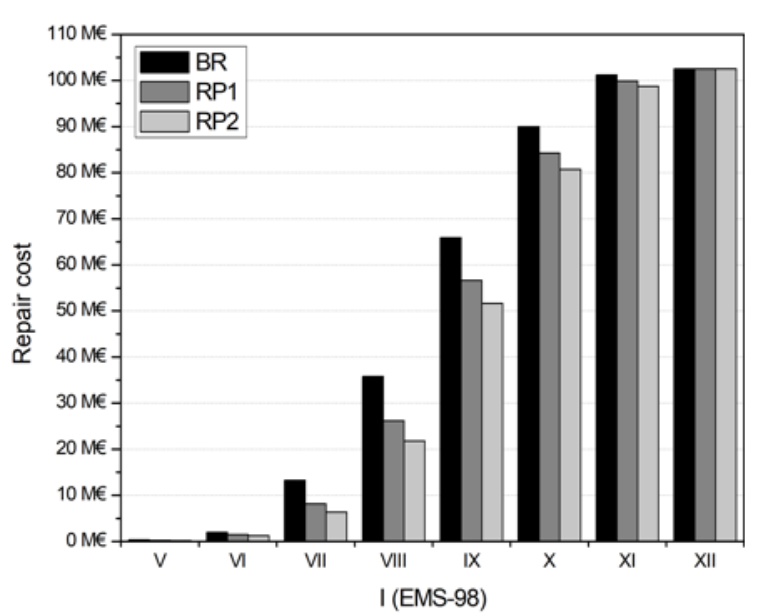

Figure 24. Evaluation of the reparation costs for the different conditions analyzed

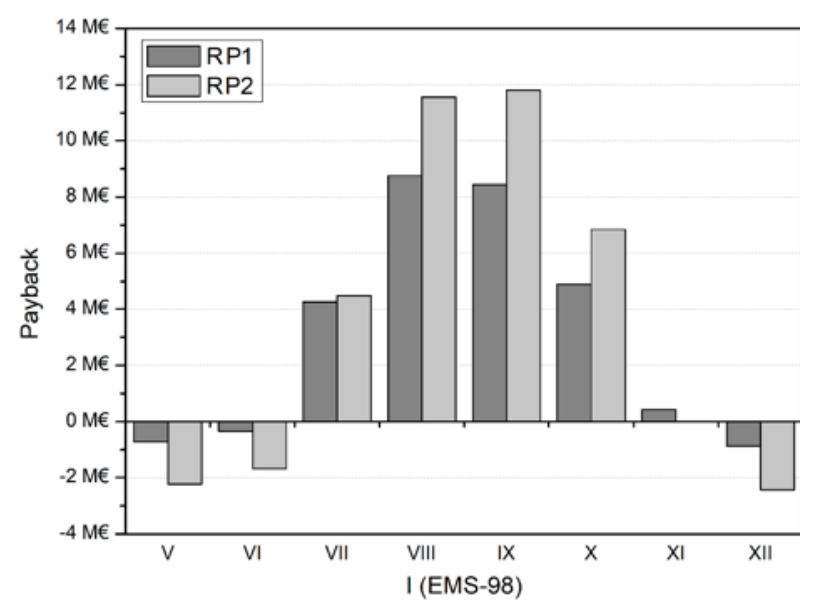

Figure 25. Evaluation of the payback amounts for the retrofitting packages applied

For low intensity earthquakes (V and VI), the initial retrofitting cost is not justified. The effectiveness range of the two intervention types are between intensities VII and X for RP1 with a payback maximum at intensity VIII of $8.75 \mathrm{M} €$ (ten times the initial investment), and for RP2 with a payback maximum at intensity IX of $11.81 €$ ( 5 times the initial investment). Beyond seismic intensity IX, the retrofitting applications start losing their effectiveness because the building stock, including the unreinforced buildings, start to suffer severe damage and collapse. 


\section{Conclusions}

488 The outcomes resulting from the vulnerability assessment prove the reliability of the method proposed by Vicente et al. (2011) and Ferreira (2017a) applied to the observed characteristics and fragilities that affect structural behavior in the case of seismic events. The most vulnerable features characterizing the building stock were the connections between the various structural elements of the buildings contributing to the box-like behavior of a structure, the masonry quality, the state of conservation, and the presence of adequately stiff floor slabs that distribute and transmit the seismic load to resisting elements. Although Leiria is located in a moderate seismic hazard area, the expected level of damage for the building stock, the potential economic losses, and casualties should be reduced by means of risk management policies aimed at ensuring a sufficient seismic safety.

The hybrid method of vulnerability assessment is based on 14 different parameters that takes into account geometrical and structural characteristics, soil-structure and structure-to-structure interactions, quality of materials and construction details, conservation state. Since this method has uncertainties related to its calibration and especially to the collection of data, it is important to assess the reliability of results through a confidence factor. The strategy followed in this work allowed for the singular evaluation of the confidence class for each parameter but needs to be improved for the evaluation of a mean confidence level related to the overall vulnerability index of each building.

Bearing in mind the structural deficiencies that characterize the building stock, retrofitting strategies were aimed at mitigating seismic risk of the historical city center. The strategies properly address the most vulnerable features of the buildings in Leiria and are evaluated in a cost-benefit analysis that, through updating the vulnerability index values and computing new mean damage grades, discrete damage grades, and loss probabilities, estimates the benefits in terms of decreasing the death toll, homelessness, and collapsed and unusable buildings after a seismic event.

In conclusion, vulnerability assessment of existing structures is crucial in seismic areas to drive risk management policies and design retrofitting interventions that address observed fragilities. Through a qualitative cost-benefit analysis the evaluation of the proposed large-scale intervention allows municipalities and decision makers to make informed decisions regarding risk prevention. Interventions should be selected and designed in a way that they effectively contribute to decrease the seismic vulnerability and, in consequence, to achieve a reduction of overall damage, loss and casualty. Moreover, to be cost-efficient, the buildings to intervene (or their parts) should be wisely selected. Local authorities are able to interpret the present work on large-scale seismic analysis because its results are presented with intuitive GIS maps, thus making them aware of potential effects of their risk management policies. Moreover, outputs can be continually updated because of the integration within the GIS tool, as well as the spreadsheet database. Potential post-earthquake scenarios can be predicted for different macro-seismic intensities and their accuracy depends on the proposed calibration that takes into account the actual features of the building stock. In addition, if the results are updated with the new population data, they can provide significant information about emergency planning since the most vulnerable buildings and areas are identified, see for example (Aguado et al. 2018) and Anglade et al. (2020).

Acknowledgements: This work was enabled and funded by the Advanced Masters in Structural Analysis of Monuments and Historic Constructions (SAHC) at the University of Minho and by the Portuguese Foundation for Science and Technology (FCT) through the postdoctoral fellowship SFRH/BPD/122598/2016. The authors would like to thank the students at the Polytechnic Institute of Leiria for their assistance in coordinating and executing fieldwork. Additionally, many thanks to the Municipality of Leiria for providing access to their records and support of the work.

\section{$531 \quad$ References}


Anglade E, Giatreli A-M, Blyth A, et al (2020) Seismic damage scenarios for the Historic City Center of Leiria, Portugal: Analysis of the impact of different seismic retrofitting strategies on emergency planning. Internatioal Journal of Disaster Risk Reduction, 44:101432. doi: 10.1016/j.ijdrr.2019.101432

Bernardini, A., Giovinazzi, S., Lagomarsino, S., and Parodi, S. (2007). "Vulnerabilità e previsione di danno a scala territoriale secondo una metodologia macrosismica coerente con la scala EMS-98." University of Canterbury. Civil and Natural Resources Engineering, Pisa, Italy (in Italian).

Borri, A., Corradi, M., Castori, G., and De Maria, A. (2015). "A method for the analysis and classification of historic masonry." Bulletin of Earthquake Engineering, 13(9), 2647-2665.

Bothara, J., and Brzev, S. (2011). A TUTORIAL: Improving the Seismic Performance of Stone Masonry Buildings. Svetlana Brzev First Edition, July 2011.

Bramerini, F., Di Pasquale, G., Orsini, A., Orsini, A., Pugliese, A., Romeo, R., and Sabetta, F. (1995). "Rischio sismico del territorio italiano. Proposta per una metodologia e risultati preliminari. Rapporto tecnico del Servizio Sismico National SSN." (in Italian).

Cansado, E., Oliveira, C. S., Fragoso, M., and Miranda, V. (1998). "Regras Gerais de Reabilitação e Reconstrução de Edifícios Correntes Afectados Pela Crise Sísmica do Faial, Pico e São Jorge, iniciada pelo sismo de 9 de Julho de 1998.” (in Portuguese).

Carvalho, V., and Aveleira, A. (n.d.). "Enquadramento histórico e arqueológico." <www.cm-leiria.pt/pages/405> (in Portuguese).

Circolare 21 gennaio 2019 n. 7 C.S.LL.PP. (2019). Circolare 21 gennaio 2019 n. 7 C.S.LL.PP. Istruzioni per l'applicazione dell'aggiornamento delle "Norme Tecniche per le Costruzioni" di cui al D.M. 17/01/2018. Suppl. ord. alla G.U. n. 35 del 11/2/19. (in Italian)

Costa, A. (2002). "Determination of mechanical properties of traditional masonry walls in dwellings of Faial Island, Azores." Earthquake Engineering and Structural Dynamics, 31(7), 1361-1382.

Costa, A., Oliveira, C. S., and Neves, N. (2008). "Reinforcing Commonly More Techniques Used in Faial Reconstruction.” In: Sismo 1998 - Açores. Uma Década Depois. Sousa Oliveira, Costa \& Nunes (Edt.), 531-555. ISBN: 978-989-20-12230 (in Portuguese)

D’Ayala, D., Spence, R., Oliveira, C., and Pominos, A. (1997). "Earthquake Loss Estimation for Europe's Historic Town Centres." Earthquake Spectra, 13(4), 773-793.

Dinis, C. (2006). Estudo Sócio - Demográfico do Centro Histórico da Cidade de Leiria - Conclusão. (in Portuguese)

Ferreira, T. M. (2010). "Avaliação da vulnerabilidade sìsmica de nùcleos urbanos antigos: Aplicação ao núcleo urbano antigo do Seixal." Universidade do Porto, Portugal. (in Portuguese)

Ferreira, T. M., Maio, R., and Vicente, R. (2017a). "Seismic vulnerability assessment of the old city centre of Horta, Azores: calibration and application of a seismic vulnerability index method." Bulletin of Earthquake Engineering, Springer Netherlands, 15(7), 2879-2899.

Ferreira, T. M., Maio, R., and Vicente, R. (2017b). "Analysis of the impact of large scale seismic retrofitting strategies through the application of a vulnerability-based approach on traditional masonry buildings." Earthquake Engineering and Engineering Vibration, 16(2), 329-348.

Ferreira, T. M., Santos, C., Vicente, R., and Mendes da Silva, J. A. R. (2015). "Structural and Architectural Characterisation of Old Building Stocks: Case Study of the Old City Centre of Seixal, Portugal, Rebuilt After the Great 1755 Lisbon Earthquake." Engineering Structures and Technologies, 7(3), 126-139.

Ferreira, T. M., Vicente, R., Mendes da Silva, J. A. R., Varum, H., and Costa, A. (2013). "Seismic vulnerability assessment of historical urban centres: case study of the old city centre in Seixal, Portugal." Bulletin of Earthquake Engineering, 11(5), $1753-1773$.

Giovanizzi, S. (2005). "The Vulnerability Assessment and the Damage Scenario in Seismic Risk Analysis." Chem. Ind., (March 2005).

GNDT. (1994). Scheda di vulnerabilità di II livello. Rome, Italy. (in Italian)

GNDT. (2003). Manuale per la compilazione della scheda GNDT/CNR di livello II - Versione modificata dalla Regione Toscana. (in Italian)

Grünthal, G. (1998). European Macroseismic Scale 1998 (EMS-98). Cahiers du Centre Européen de Géodynamique et de Séismologie 15. Centre Européen de Géodynamique et de Séismologie, Luxembourg.

Frank J. Massey Jr. (1951) "The Kolmogorov-Smirnov Test for Goodness of Fit”, Journal of the American Statistical Association, 46(253): 68-78. doi: 10.1080/01621459.1951.10500769 
Maio R, Ferreira T. M., Vicente R., Costa A. (2019) Is the use of traditional seismic strengthening strategies economically attractive in the renovation of urban cultural heritage assets in Portugal? Bulletin of Earthquake Engineering 17:23072330. doi: 10.1007/s10518-018-00527-7

Maio, R., Ferreira, T. M., Vicente, R., and Estêvão, J. (2016). "Seismic vulnerability assessment of historical urban centres: case study of the old city centre of Faro, Portugal." Journal of Risk Research, 19(5), 551-580.

Mattoso, J. (1985). “A cidade de Leiria na historia medieval de Portugal.” Ler historia $n^{\circ} 4,2-19$. (in Portuguese)

Oliveira, C. S., Lucas, A., and Guedes, J. H. C. (1990). MONOGRAFIA - 10 Anos após o Sismo dos Açores de 1 de Janeiro de 1980 - Volume I e II. Secretaria Regional da Habitação e Obras Públicas, Delegação da Ilha Terceira, Açores, Laboratório Nacional de Engenharia Civil, Angra do Heroísmo, Açores, Portugal. (in Portuguese)

Penna A. (2015) Seismic assessment of existing and strengthened stone-masonry buildings: critical issues and possible strategies. Bull Earthq Eng 13:1051-1071. doi: 10.1007/s10518-014-9659-0

Pinheiro, P., Fernandes, P., Santos, P., and Rodrigues, H. (2017). "Mechanical Characterization of Masonry Walls With FlatJack Tests." Nondestructive Techniques for the Assessment of Historic Structures, CRC Press, 53-73.

dos Santos Gomes, T. M. (2016). "Caracterização do Parque Edificado do Centro Histórico de Leiria.”. MSc Thesis. Istituto Politécnico de Leiria, Portugal. (in Portuguese)

Teves-Costa P., Batlló J., Matias L., Catita, C., Jiménez, M. J. García-Fernández, M. (2019) Maximum intensity maps (MIM) for Portugal mainland. Journal of Seismology 23:417-440. doi: 10.1007/s10950-019-09814-5

Tomaževič, M. (1999). Earthquake-resistant Design of Masonry Buildings. Imperial College Press, London.

Vicente, R. (2008). "Estratégias e metodologias para intervenções de reabilitação urbana Avaliação da vulnerabilidade e do risco sísmico do edificado.". PhD Thesis. Universidade de Aveiro. (in Portuguese)

Vicente R., Parodi S., Lagomarsino S., Varum, H. and Mendes da Silva, J. A. R. (2011) Seismic vulnerability and risk assessment: case study of the historic city centre of Coimbra, Portugal. Bulletin of Earthquake Engineering 9:10671096. doi: 10.1007/s10518-010-9233-3

Vicente, R., Ferreira, T. M., and Mendes da Silva, J. A. R. (2015). "Supporting urban regeneration and building refurbishment. Strategies for building appraisal and inspection of old building stock in city centres." Journal of Cultural Heritage, Elsevier Masson SAS, 16(1), 1-14. 